\title{
Pneumatic Boxing Glove Reduces Upward Drift in Peak Force and Loading Rate over a Long Series of Impacts
}

\author{
Paul Perkins' 1,2, Alex Jamieson1, Wayne Spratford1, Allan Hahn"1,3,4 \\ ${ }^{1}$ University of Canberra, Canberra, Australia \\ ${ }^{2}$ Boxing Australia Limited, Canberra, Australia \\ ${ }^{3}$ Queensland Academy of Sport, Brisbane, Australia \\ ${ }^{4}$ Griffith University, Brisbane, Australia \\ Email: paul.perkins@boxing.org.au
}

How to cite this paper: Perkins, P., Jamieson, A., Spratford, W. and Hahn, A. (2019) Pneumatic Boxing Glove Reduces Upward Drift in Peak Force and Loading Rate over a Long Series of Impacts. World Journal of Engineering and Technology, 7, 18-53.

https://doi.org/10.4236/wjet.2019.71002

Received: November 8, 2018

Accepted: December 17, 2018

Published: December 20, 2018

Copyright $(0) 2019$ by authors and Scientific Research Publishing Inc. This work is licensed under the Creative Commons Attribution International License (CC BY 4.0).

http://creativecommons.org/licenses/by/4.0/

\begin{abstract}
A conventional boxing glove and a prototype pneumatic glove were each fitted to a mechanical fist and dropped 253 times from a height of 3 metres on to a force plate covered by an ethylene vinyl acetate (EVA) mat. Impact dynamics were measured and modelled. From the outset, peak impact force and peak rate of force development (loading rate) were lower for the pneumatic glove. For both gloves, these variables displayed upward drift during the drop series, but the drift was smaller for the pneumatic glove. Consequently, the magnitude of the protective effect provided by the pneumatic glove increased with the number of impacts. For the conventional glove, change in peak force showed a close inverse relationship to force plate contact time $\left(\mathrm{R}^{2}>0.96\right)$ and the time from first contact of the glove with the force plate to attainment of peak force $\left(R^{2}=0.85\right)$. These relationships were much weaker for the pneumatic glove $\left(R^{2}=0.09\right.$ and 0.59 respectively), suggesting the possibility of a more complex impact damping mechanism. Following the 253 drops of the pneumatic glove, the EVA mat covering the force plate was replaced, and another 10 drops then performed. Peak force readings were immediately reduced to an extent suggesting that $26 \%-34 \%$ of the increase that had occurred over the 253 drops was attributable to impact-induced change in mat properties. This has implications for future experimental designs. Overall, the findings provided further evidence of the potential of pneumatic gloves to enable safer boxing.
\end{abstract}

\section{Keywords}

Boxing Safety, Low-Impact Boxing Gloves, Modified Boxing, 
Pneumatic Boxing Gloves, Protective Equipment for Boxing, Sport Technology, Sport Safety

\section{Introduction}

We have recently described experiments showing that, compared to conventional boxing gloves, a pneumatic boxing glove with a bladder capable of air exchange with the external environment can substantially reduce peak impact forces delivered to a target, and provide even greater reduction in peak rate of force development [1], also known as loading rate. This protection is afforded across a wide range of pre-impact glove velocities extending to the average maximum levels observed by Walilko et al. [2] for elite boxers and has been found to exist even when target characteristics are markedly altered [3].

Suitability of the pneumatic gloves for field use will depend not just on their immediate protectiveness but also on their robustness in the face of multiple impacts. Our initial research [1] entailed repeatedly dropping them from heights of 1 - 5 metres on to a force plate covered by ethylene vinyl acetate (EVA) material, but the maximum number of drops per glove in any one experiment was 90 , with 40 of these conducted from drop heights of 2.5 metres or less. We perceived a need to determine whether the gloves could withstand a much larger number of impacts of moderate to high magnitude without occurrence of structural damage and/or significant deterioration in performance.

Our early studies entailed evaluation of two different prototype pneumatic gloves and two conventional gloves that differed in mass. When we combined data from all gloves across all drop heights, we observed a tendency for peak force readings to gradually increase over a series of 10 drops [1]. While we thought this was probably due largely to "bedding down" of gloves on to a mechanical fist inserted into them, it was apparent that progressive glove compression might play a role. This amplified our interest in ascertaining how the gloves might be affected by a large number of impacts under conditions of controlled pre-impact velocity.

Available evidence indicates that professional boxers land an average of $\sim 18$ punches to the designated target area of the opponent per 3-minute round [4]. According to data provided by an automated scoring system in which contacts to the target zones were recorded by sensors, accomplished amateur boxers landed an average of $\sim 27$ impacts per round [5]. Use of the same automated scoring system in a modified boxing (Box'Tag) context revealed an average of 28 scoring impacts per boxer per round [6], even though the rounds in this context were of shorter duration. In each situation, there would have been additional impacts to non-scoring areas. Given that a single pair of conventional boxing gloves can sometimes remain in frequent use for 2 - 5 years [7] [8] for training purposes including sparring, the ability of gloves to maintain integrity and performance over the course of numerous impacts is clearly important. 
In light of the above, we compared a prototype pneumatic glove to a conventional glove in terms of changes in measured impact parameters during a long sequence of successive impacts. We aimed to describe and model the changes and to obtain improved understanding of their mechanisms.

\section{Methods}

A pneumatic glove incorporating a bladder enabling air release upon impact and subsequent air reuptake (ARLI glove) and a conventional $10 \mathrm{oz}$ boxing glove (Std $10 \mathrm{oz}$ ) each underwent 253 consecutive drops on to a Kistler force plate (Kistler, Amherst, MA) from a height of 3 metres. Each glove was placed securely on to a mechanical fist that of itself had a mass of $3.046 \mathrm{~kg}$. The drop testing apparatus is described in detail elsewhere [1]. It consisted of a flanged, low-friction pulley attached to a wall-mounted frame such that the pulley was located at a height of 5.5 metres directly above the centre of the force plate. A cord placed over the pulley allowed gloves to be drawn up to any required drop height. The cord was pulled through an eyelet on a post secured to the laboratory floor. Alignment of markings on the cord with the edge of the eyelet ensured drop height accuracy. The force plate had a surface area of $600 \mathrm{~mm} \times 400 \mathrm{~mm}$ and was covered by a mat of EVA 75 material (Ultralon Foam Group, Sydney, Australia) with a thickness of $25 \mathrm{~mm}$ and a guaranteed JIS hardness (as measured by an Asker Type C Hardness Tester) of 30 - 35 degrees. The ARLI glove was produced by Stellen Studio (Canberra, Australia) and had a mass of $342 \mathrm{~g}(12.1 \mathrm{oz})$. The Std $10 \mathrm{oz}$ glove was made by Sting Sports (Melbourne, Australia) and had a mass of $275 \mathrm{~g}(9.7 \mathrm{oz})$. The two gloves are pictured in Figure 1, which shows that they had quite similar dimensions. The height of the Std $10 \mathrm{oz}$ glove was $26.5 \mathrm{~cm}$ while that of the ARLI glove was $27.5 \mathrm{~cm}$. The main section of the $S t d 10 \mathrm{oz}$ glove (the section not including the thumb) had a maximum width of $13.0 \mathrm{~cm}$ and a circumference of $43.0 \mathrm{~cm}$. Corresponding measurements for the ARLI glove were 12.5 and $40.0 \mathrm{~cm}$.

It was planned that for each glove 250 drops would be performed in five blocks of 50. In practice, the third block for the Std $10 \mathrm{oz}$ glove was extended to 53 drops, while for the ARLI glove Blocks 4 and 5 consisted of 51 and 52 drops respectively. This meant that in fact there were 253 drops of each glove. Intervals between the end of one block and the start of the next are shown in Table 1.

Within each block, there were five sub-blocks of $10-12$ drops, separated by 2 - 6 minutes. The sub-blocks had durations of $4-10$ minutes, with an average of 6.4 minutes for the Std $10 \mathrm{oz}$ glove and 6.0 minutes for the ARLI glove.

The intervals were included partly for practical reasons but also in the hope that they would enable insights into the time course of glove recovery after a series of impacts. We attempted to rigorously adhere to a pre-set timetable with a view to making intervals for the Std $10 \mathrm{oz}$ and ARLI gloves identical. Although experimental practicalities prevented this from being fully achieved, variations in the intervals between the two days of testing were minor. 

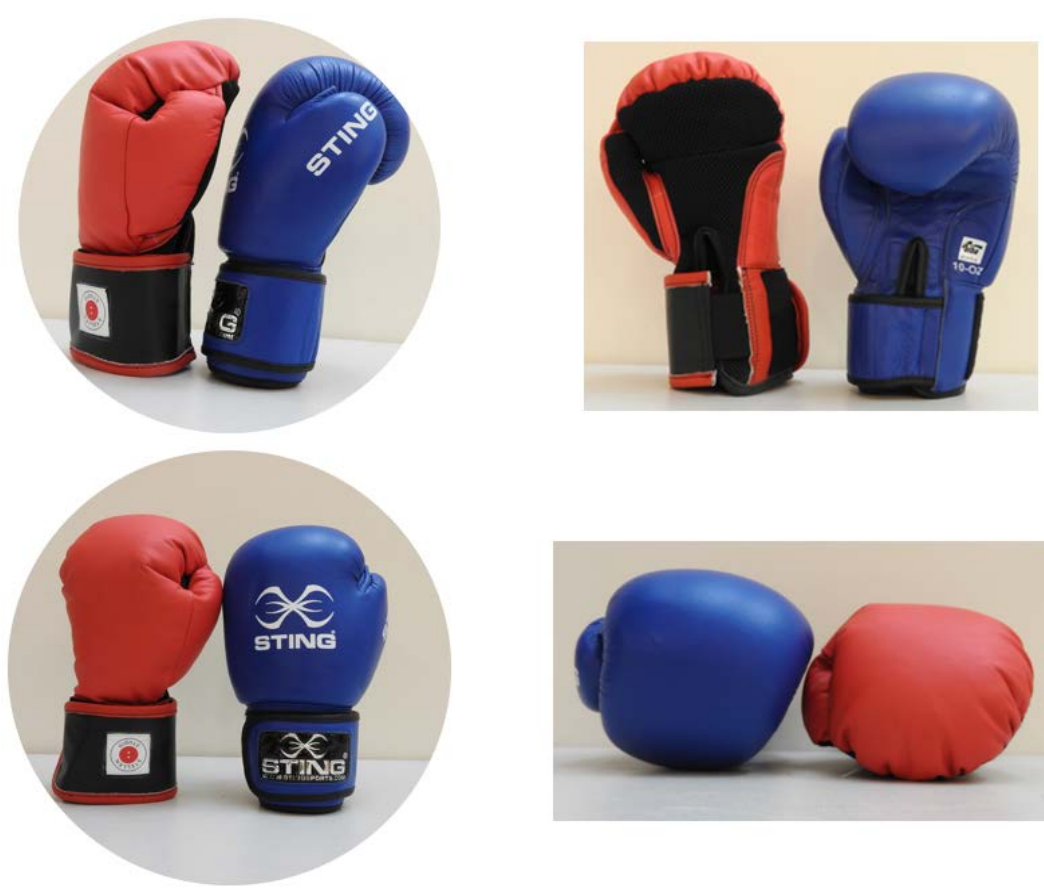

Figure 1. The Std $10 \mathrm{oz}$ (blue) and ARLI (red) gloves employed in the study.

Table 1. Intervals between successive blocks of 50 drops in the testing of Std $10 \mathrm{oz}$ and ARLI gloves.

\begin{tabular}{ccc}
\hline & Std 10 oz & ARLI \\
\hline Block 1 - Block 2 & $9 \mathrm{~min}$ & $13 \mathrm{~min}$ \\
Block 2 - Block 3 & $10 \mathrm{~min}$ & $4 \mathrm{~min}$ \\
Block 3 - Block 4 & $6 \mathrm{~min}$ & $10 \mathrm{~min}$ \\
Block 4 - Block 5 & $73 \mathrm{~min}$ & $71 \mathrm{~min}$ \\
\hline
\end{tabular}

The ARLI glove was tested first, with the testing of the Std $10 \mathrm{oz}$ glove taking place exactly one week later. On both occasions, Kistler Bioware software was used to set force plate parameters and to record force plate data at a sampling rate of $10,000 \mathrm{~Hz}$. The software was run on a standard PC. Known masses were regularly placed on the force plate to check the consistency of readings.

After completion of the 253 drops of the ARLI glove, the EVA 75 mat covering the force plate was replaced with another of the same type and dimensions, and a further 10 drops of the glove were then performed. The intention was to determine whether receipt of multiple impacts by the original mat had altered its properties in a way that affected measured impact dynamics. The first drop of the glove on to the new mat occurred three minutes after the preceding impact. The original and new mats were purchased from the same retailer but several weeks apart. This makes it unlikely that they came from the same production batch. Consequently, their qualities may not have been absolutely identical, although the Ultralon Foam Group carefully controls the manufacturing of its EVA 75 material to meet well-defined specifications [9]. 


\section{Results}

The peak impact forces recorded for the two gloves are shown in Figure 2. Several points are immediately evident. For any given point in the series of drops, readings for the Std $10 \mathrm{oz}$ glove were substantially higher than those for the ARLI glove. There was upward drift in the readings for both glove types, but the extent of this drift was much greater for the Std 10 oz glove, meaning that the difference in peak force between the two glove types tended to increase as a function of the number of glove drops.

For both gloves, the relatively long intervals between successive blocks of 50 53 glove drops were generally associated with reduced peak forces readings for the first glove drop after the interval (indicated by the black circles in Figure 2). The longest interval, between Blocks 4 and 5, led to a subsequently much decreased initial reading for the Std $10 \mathrm{oz}$ glove, but the readings then rapidly increased, and although they were generally below the levels recorded in Block 4, they exceeded the levels for Block 3. The long break between Blocks 4 and 5 had little influence on the progression of readings for the ARLI glove. For both glove types, any influence of the shorter intervals between sub-blocks of glove drops was minor and difficult to detect.

Also apparent in Figure 2 is the fact that toward the end of Block 3, peak force readings for the Std $10 \mathrm{oz}$ glove quite suddenly became elevated beyond a level that could be predicted from the preceding drops, with this elevation continuing through to the end of Block 4 .

In an attempt to identify possible reasons for the sudden change in the peak forces for the Std 10 oz glove, we used the 3D Vector function provided by the Kistler Bioware software to examine the force plate impact profile for every drop of the glove. For completeness, we did likewise for the ARLI glove. Typical profiles for the two gloves are presented in panels A and B of Figure 3, while the profile for the $141^{\text {st }}$ drop of the Std $10 \mathrm{oz}$ glove appears in panel C.

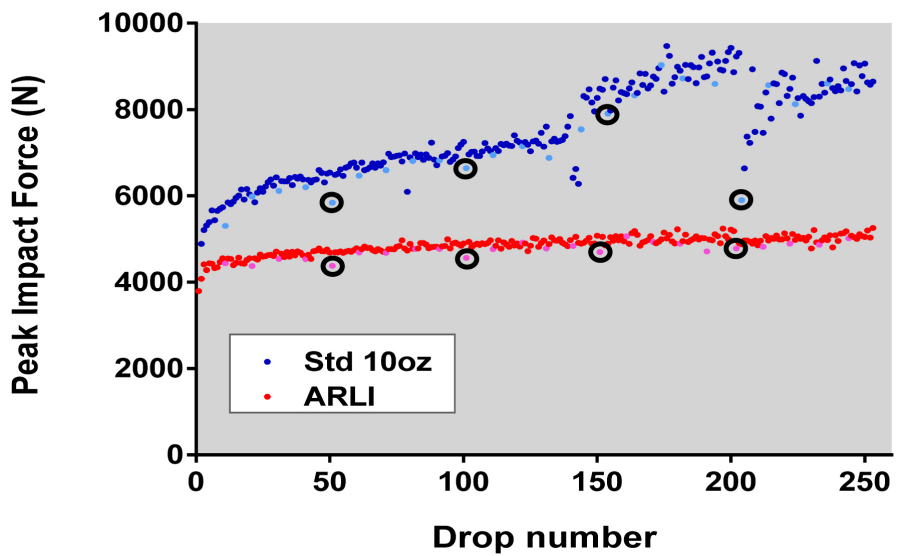

Figure 2. Change in peak impact forces for two different glove types over the course of 253 drops on to a force plate from a height of 3 metres. The first data points of Blocks 2 5 are indicated by the black circles, and the first data points of each sub-block of $10-12$ drops are shown in lighter colours. 


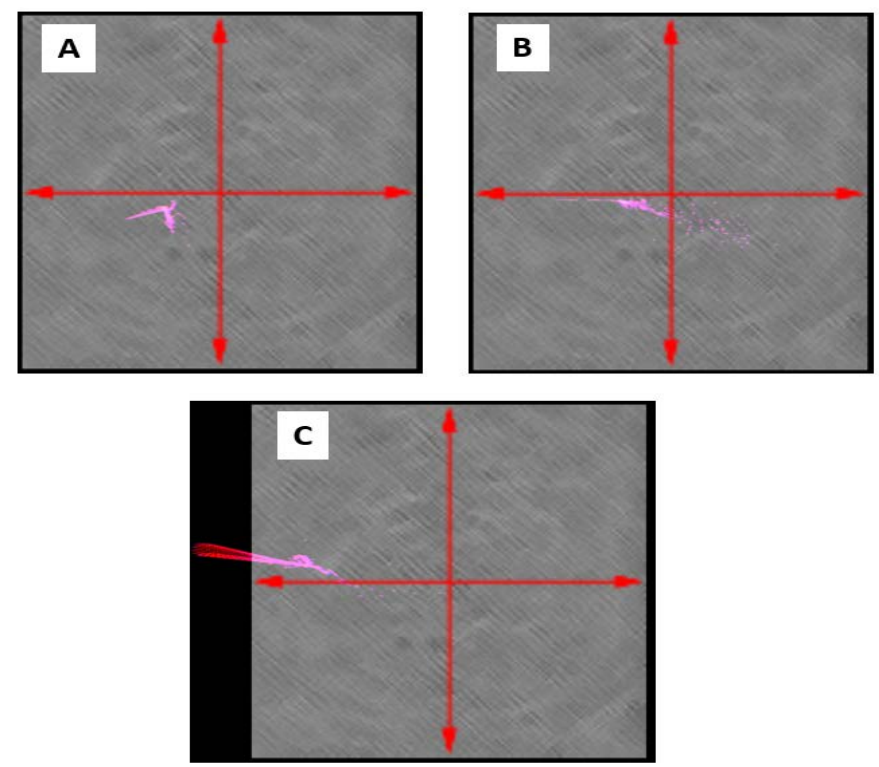

Figure 3. Force plate profiles associated with impacts resulting from dropping of Std 10 $\mathrm{oz}$ and ARLI gloves. Panel $\mathrm{A}=$ representative profile for Std $10 \mathrm{oz}$ glove, Panel B = representative profile for ARLI glove, Panel $\mathrm{C}=141^{\text {st }}$ drop of Std $10 \mathrm{oz}$ glove.

For the $141^{\text {st }}$ drop of the Std 10 oz glove, the initial point of contact was relatively close to the front edge (left side in the schematic) of the force plate, and the subsequent propagation of force extended beyond the force plate boundary. Drops 117 and 230 of the Std 10 oz glove produced somewhat similar outcomes, as did drops 67, 114, 117, 191 and 208 of the ARLI glove, but in none of these cases was the effect so pronounced (see Figure 4).

Although the problem was confined to just $\sim 1.5 \%$ of all glove drops, we sought to ascertain the reasons for its occurrence. We determined the force plate impact locations for every glove drop with both glove types. Using Kistler Bioware schematics such as those shown above, and with the aid of colour coding and moving displays of force propagation provided by the Bioware software, we identified and marked the centre point of each impact. A transparent $20 \times 20$ grid was then electronically superimposed on to the schematic to facilitate identification of $X$ and $Y$ co-ordinates for the mark. For example, the coordinates for the glove drop represented in Figure 5 were deemed to be $X=-22$ and $Y=-11$.

The impact locations so identified are presented in Figure 6, which reveals that there was an overall tendency for the gloves to land forward of the centre of the force plate. This was despite our preparatory use of a plumb line to ensure that the pulley used to raise the gloves to the required drop height was positioned directly over the centre point. The white circles in the figure denote the above-mentioned problematic impacts and highlight the fact that the most forward landings were the most likely to cause failure of containment of force propagation within the force plate boundaries, although impact location was not the sole determinant of such failure.

Seven of the eight glove drops that resulted in impact forces traversing the 

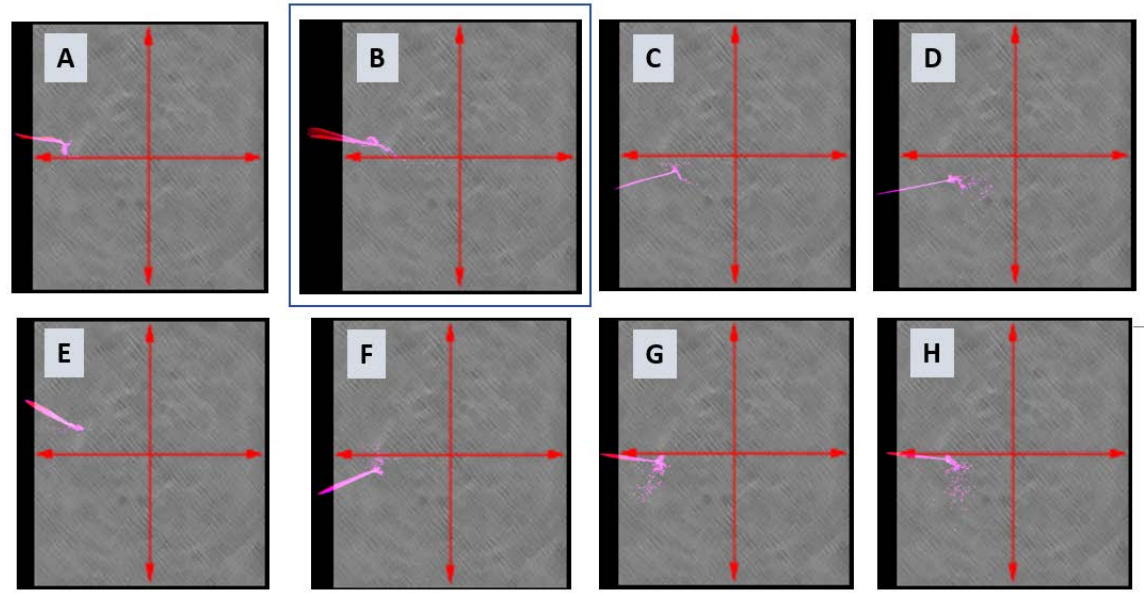

Figure 4. Force plate profiles for each of eight glove drops in which force propagation extended beyond the force plate boundary. A = Drop 117 with Std 10 oz glove, B = Drop 141 with Std $10 \mathrm{oz}$ glove, C = Drop 230 with Std $10 \mathrm{oz}$ glove, D = Drop 67 with ARLI glove, $\mathrm{E}=$ Drop 114 with ARLI glove, $\mathrm{F}=$ Drop 117 with ARLI glove, $\mathrm{G}=$ Drop 191 with ARLI glove, $\mathrm{H}=$ Drop 208 with ARLI glove.

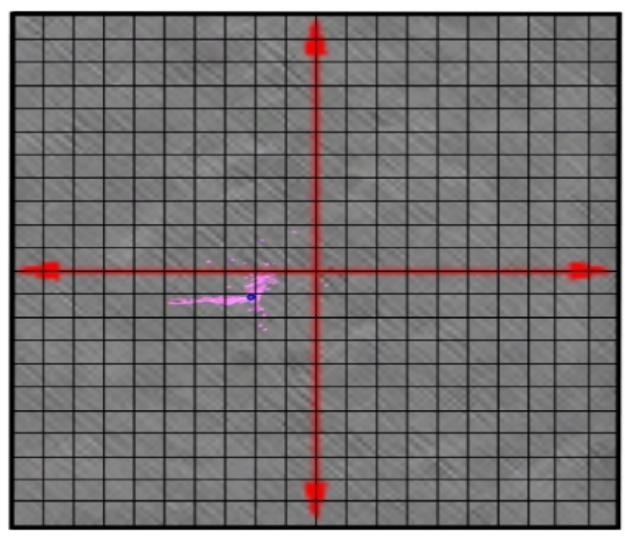

Figure 5. Use of Kistler Bioware schematic and a superimposed grid to identify centres of impact for glove drops.
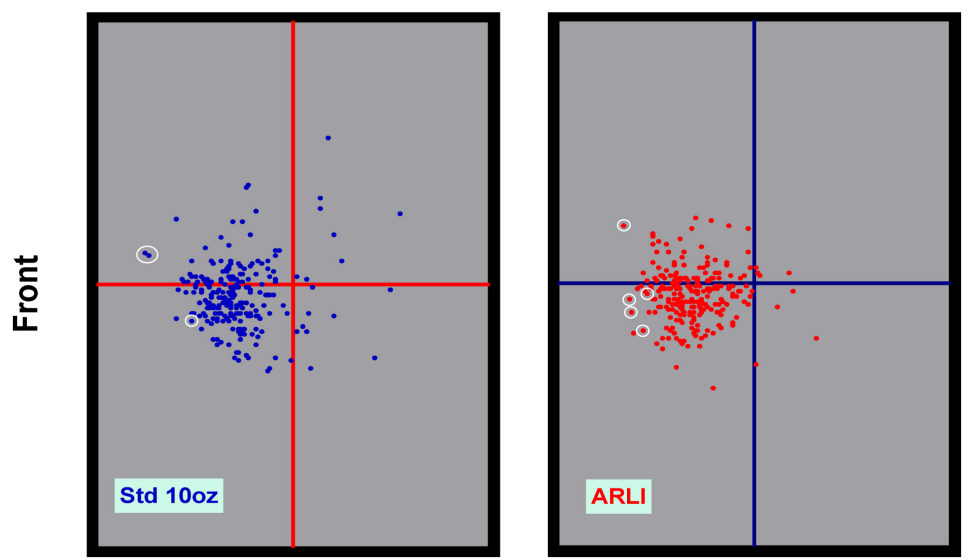

Figure 6. Centres of impact for 253 drops of Std $10 \mathrm{oz}$ (left panel) and ARLI (right panel) gloves on to a force plate from a height of 3 metres. The white circles identify glove drops in which force propagation extended beyond the boundaries of the force plate. 
boundaries of the force plate had no discernible or lasting effect on the progression of peak forces with subsequent drops, but such an effect was evident in the case of the $141^{\text {st }}$ drop of the Std $10 \mathrm{oz}$ glove. Accordingly, we decided that for data modelling purposes analysis of the response of the Std $10 \mathrm{oz}$ glove to repeated impacts should be limited to the first 140 glove drops, whereas analysis of the performance of the ARLI glove could be based on all 253 drops. For both glove types data obtained from the problematic drops were removed, after which there were 139 valid observations for the Std $10 \mathrm{oz}$ glove and 248 valid observations for the ARLI glove.

Since the increase in peak force over the series of glove drops was curvilinear for both glove types, with a rapid early increase followed by slower subsequent rise (see Figure 2), we plotted the logarithm of peak force against the logarithm of drop number, which made the relationship more linear. We then applied linear regression analysis to the logarithmic data and used the results to develop power equations that fitted the data. Each power equation was determined as the antilogarithm of the intercept provided by the linear regression analysis multiplied by the drop number raised to the power of the slope provided by the linear regression analysis. Because we wanted to compare predictive models for the two glove types, it was necessary to evaluate the possible effects of using different numbers of observations to develop the models. Consequently, for the ARLI glove, we produced two separate models, one based on all 248 valid observations and the other just on the first 140 glove drops, of which 137 were valid.

Key results of the linear regression analysis conducted to determine relationships between peak force and drop number are presented in Table 2. For each of the three models, the linear regression equations revealed that more than $80 \%$ of the variance in the logarithm of peak force could be explained by variance in the

Table 2. Results of statistical analysis used to develop a power regression model relating peak force to drop number for two different glove types, with the model for the Std $10 \mathrm{oz}$ glove derived from 139 glove drops (140 minus one problematic), one model for the ARLI glove derived from 137 drops (140 minus three problematic), and another model for the ARLI glove derived from 248 drops (253 minus five problematic).

\begin{tabular}{|c|c|c|c|}
\hline & Std $10 \mathrm{oz}(139)$ & ARLI (137) & ARLI (248) \\
\hline $\begin{array}{l}\text { Linear regression } \\
\text { equation based on } \\
\text { logarithmic values }\end{array}$ & $Y=(0.09222 * X)+$ & $\begin{array}{c}Y=\left(0.04106^{*} X\right)+ \\
3.604\end{array}$ & $\begin{array}{c}Y=(0.04217 * X)+ \\
3.602\end{array}$ \\
\hline $\mathrm{R}^{2}$ & 0.9206 & 0.8334 & 0.8244 \\
\hline $\begin{array}{l}\text { Probability that true slope } \\
\text { is zero }\end{array}$ & $\mathrm{P}<0.0001$ & $\mathrm{P}<0.0001$ & $\mathrm{P}<0.0001$ \\
\hline Power equation & $Y=4581.9^{*} X^{0.09222}$ & $\mathrm{Y}=4017.9^{*} X^{0.04106}$ & $Y=3999.5^{*} X^{0.04217}$ \\
\hline $\begin{array}{l}\text { Standard deviation } \\
\text { of residuals (Sy.x) } \\
\text { for power curve }\end{array}$ & 168.63 & 80.15 & 90.86 \\
\hline $\begin{array}{l}\text { Sy.x as \% of highest \& } \\
\text { lowest observed values }\end{array}$ & $2.1,3.7$ & $1.0,2.1$ & $1.7,2.4$ \\
\hline
\end{tabular}


logarithm of drop number, and in each case the slope of the line obtained from the linear regression analysis was significantly different from zero. Subsequent one-way analysis of variance (ANOVA) showed that the slope for the Std $10 \mathrm{oz}$ glove was significantly greater than that associated with either of the models for the ARLI glove $(\mathrm{P}<0.0001)$. The slopes for the two ARLI models were not significantly different from each other $(\mathrm{P}=0.9432)$. The standard deviations of the differences between peak force values predicted from the derived power equations and the raw observed values were small, representing $2.1 \%$ and $3.7 \%$ of the highest and lowest readings respectively for the Std $10 \mathrm{oz}$ glove and being even smaller for the ARLI glove. This indicates good fit of the models to the data on which they were based.

In Figure 7, peak forces calculated by using the above power regression models are shown for a series of 250 glove drops. It can be seen that the two different models for the ARLI glove produced essentially identical results. For the Std 10 oz glove, the peak impact force for drop 250 is 1.66 times that determined for Drop 1. For the ARLI glove the corresponding figure is 1.25 - 1.26.

Figure 8 shows how the number of drops influences the reduction in force afforded by the ARLI glove relative to the Std $10 \mathrm{oz}$ glove, based on the data above. The modelling indicates that for Drop 1 the protective effect of the ARLI glove is $\sim 12.5 \%$, but that by Drop 10 it has already risen to more than $22 \%$. Thereafter, it keeps gradually rising, reaching $\sim 34 \%$ by Drop 250 . Accordingly, it is clear that the magnitude of the protective effect is dependent on the point of its determination within a drop series.

We applied the above method of analysis to all measured impact parameters, since in each case linear regression analysis of logarithmic values provided better fitting of the data than similar analysis of raw values.

Raw data for peak rate of force development are shown in Figure 9. Rate of

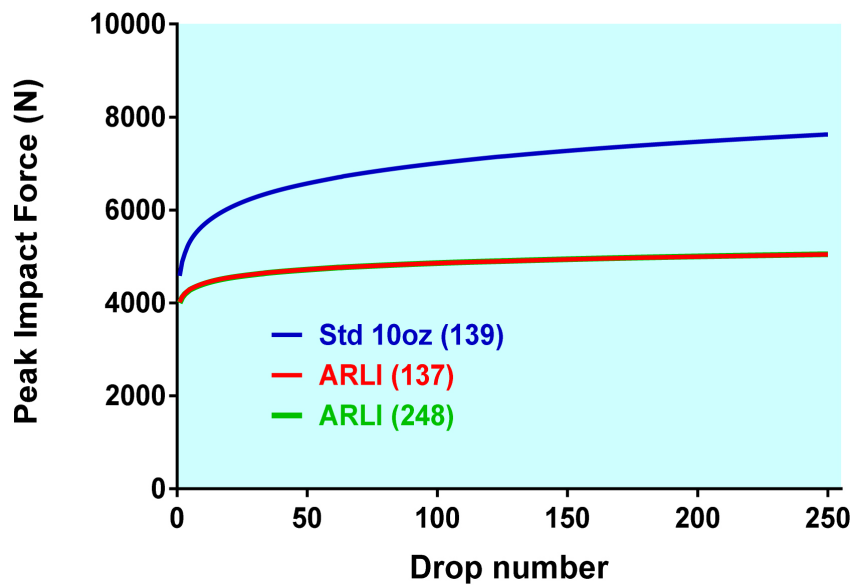

Figure 7. Peak impact forces for Std $10 \mathrm{oz}$ and ARLI gloves, as indicated by regression models derived from 139 valid observations for the Std $10 \mathrm{oz}$ glove, the first 137 valid observations for the ARLI glove, and all 248 valid observations for the ARLI glove. The line for the model based on 248 drops of the ARLI glove is drawn thicker than the others to make it visible. 


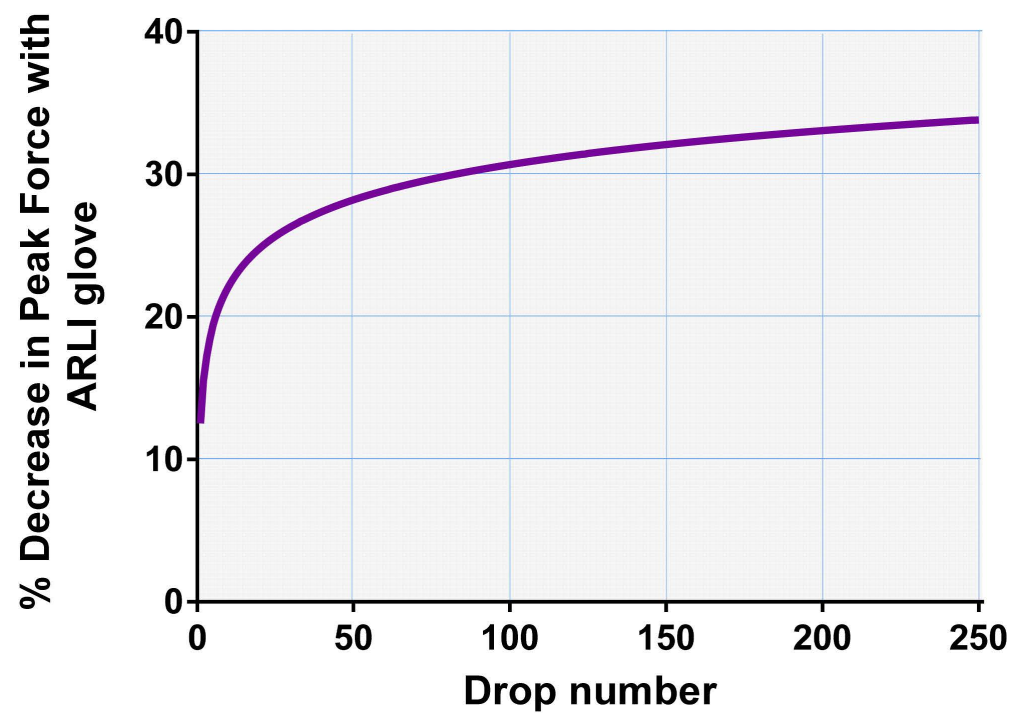

Figure 8. Percentage reduction in peak impact force provided by ARLI glove relative to Std $10 \mathrm{oz}$ glove over a series of 250 glove drops on to a force plate from a height of 3 metres, as indicated by application of power regression models derived from real laboratory observations. Data from two different models determined for the ARLI glove are combined by averaging, since the models produced essentially identical results.

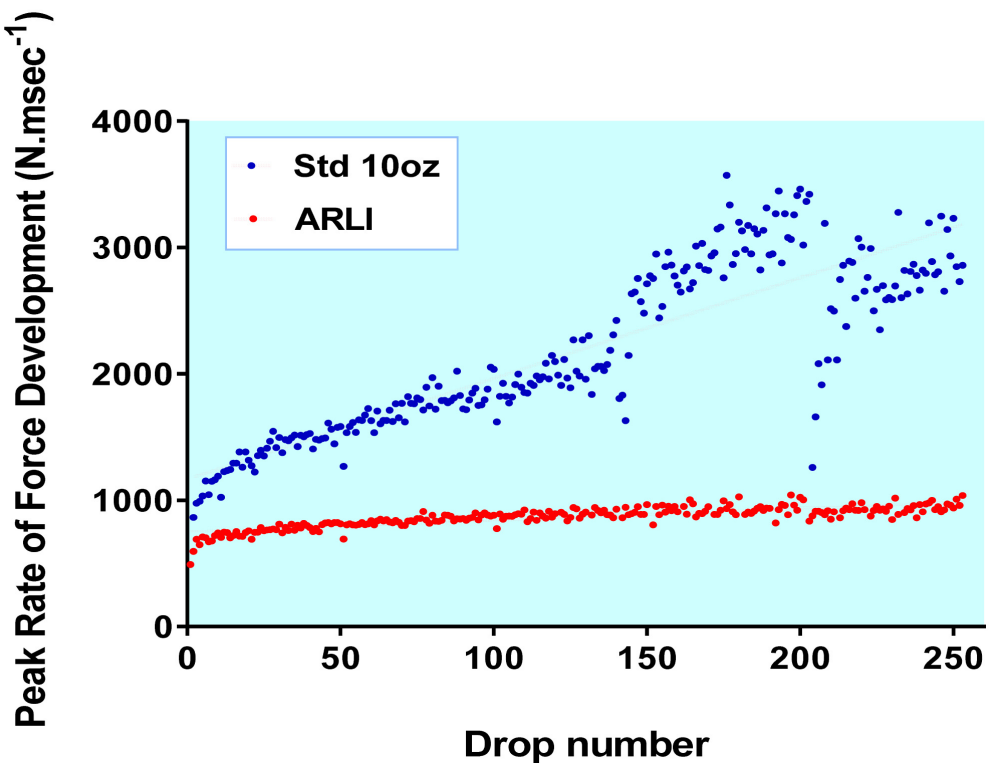

Figure 9. Raw data showing change in peak rate of force development for two different gloves over 253 drops on to a force plate from a height of 3 metres.

force development was calculated as the change in force over successive running periods of $0.5 \mathrm{msec}$, with each result then multiplied by two to provide a reading in $\mathrm{N} \cdot \mathrm{msec}^{-1}$. Again, disruption in the progression of readings for the Std $10 \mathrm{oz}$ glove from Drop 141 onwards is evident, justifying our decision to use only the first 140 drops of that glove for data modelling. Even within this limitation, it is apparent that the variability of readings was larger for the Std $10 \mathrm{oz}$ glove than the ARLI glove. 
Outcomes of statistical analysis for peak rate of force development are presented in Table 3 and are qualitatively similar to those obtained for peak impact force. All three logarithmic linear regression equations had a positive slope that was significantly different from zero. One-way ANOVA revealed that the slope for the Std $10 \mathrm{oz}$ glove was significantly $(\mathrm{P}<0.0001)$ steeper than that for either of the ARLI glove models, which were not significantly different from each other $(\mathrm{P}=0.9797)$. For each of the models, the $\mathrm{R}^{2}$ value indicated that more than $80 \%$ of the variation in the logarithm of the peak rate of force development was explicable in terms of change in the logarithm of drop number. In the case of the Std $10 \mathrm{oz}$ glove, the standard deviation of residuals associated with fitting of the power equation shown in Table 3 to the raw data was relatively high, reflecting the greater variability of the raw scores.

Changes in peak rate of force development as a function of number of glove drops, as determined from the power regression equations, appear in Figure 10, with values generated by the ARLI model based on 137 valid drops effectively indistinguishable from those produced by the model derived from 248 drops. For the Std $10 \mathrm{oz}$ glove, the peak rate of force development for Drop 250 is higher than that for Drop 1 by a factor of 3.20, whereas for the ARLI glove this factor is 1.68.

Figure 11 shows that the relative protective effect of the ARLI glove increased with drop number, being $\sim 21 \%$ for Drop 1, rising to $\sim 39 \%$ by Drop 10 and reaching $\sim 58 \%$ by Drop 250 .

Measured contact times between glove and force plate are presented in Figure 12. The contact time was defined as the period between first occurrence of a force exceeding $10 \mathrm{~N}$ in the ascending phase of the force curve and a return to a force less than $10 \mathrm{~N}$ in the descending phase. The definition was adopted in consequence of prior observations that the baseline electrical "noise" in the force

Table 3. Results of linear regression analysis relating the logarithm of peak rate of force development to the logarithm of drop number for two different glove types, with the model for the Std $10 \mathrm{oz}$ glove derived from 139 glove drops, one model for the ARLI glove derived from 137 drops, and another model for the ARLI glove derived from 248 drops.

\begin{tabular}{cccc}
\hline & Std 10 oz (139) & ARLI (137) & ARLI (248) \\
\hline $\begin{array}{c}\text { Linear regression } \\
\text { equation based on } \\
\text { logarithmic values }\end{array}$ & $Y=(0.2104 * X)+2.852$ & $Y=\left(0.09353^{*} X\right)+$ & $Y=\left(0.09453^{*} X\right)+2.75$ \\
$\mathrm{R}^{2}$ & 0.9166 & 0.8547 & 0.8262 \\
$\begin{array}{c}\text { Probability that true } \\
\text { slope is zero }\end{array}$ & $\mathrm{P}<0.0001$ & $\mathrm{P}<0.0001$ & $\mathrm{P}<0.0001$ \\
$\begin{array}{c}\text { Power equation } \\
\text { Standard deviation of } \\
\text { residuals (Sy.x) } \\
\text { for power curve }\end{array}$ & $Y=711.2 * X^{0.2104}$ & $Y=563.6^{*} X^{0.0935}$ & $Y=562.3 * X^{0.0945}$ \\
$\begin{array}{c}\text { Sy.x as \% of highest } \& \\
\text { lowest observed values }\end{array}$ & 105.00 & 28.34 & 36.42 \\
\hline
\end{tabular}




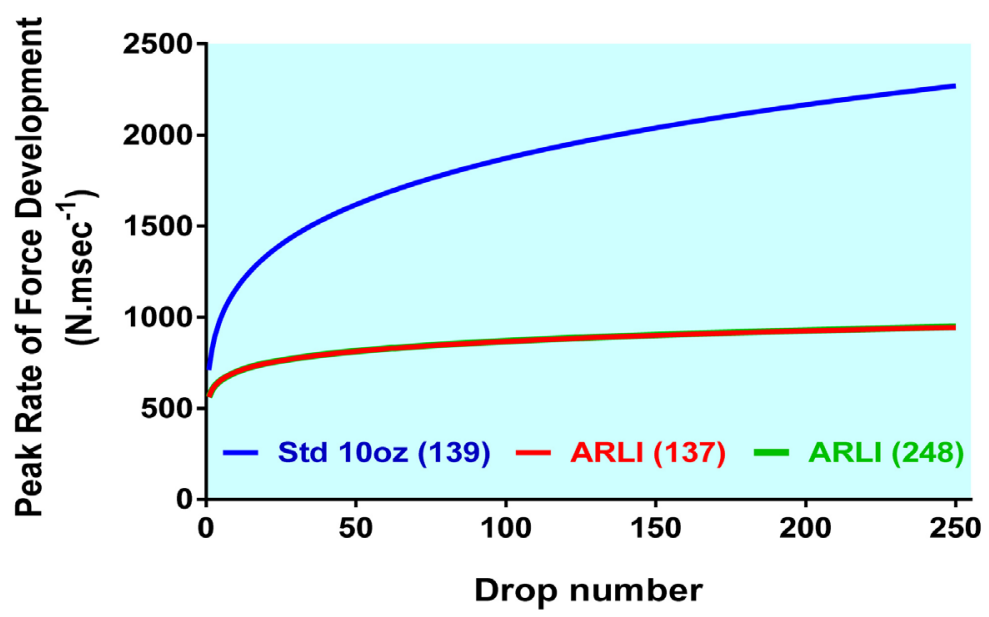

Figure 10. Peak rates of force development for Std $10 \mathrm{oz}$ and ARLI gloves, as indicated by power regression models derived from 139 valid observations for the Std $10 \mathrm{oz}$ glove, the first 137 valid observations for the ARLI glove, and all 248 valid observations for the ARLI glove.

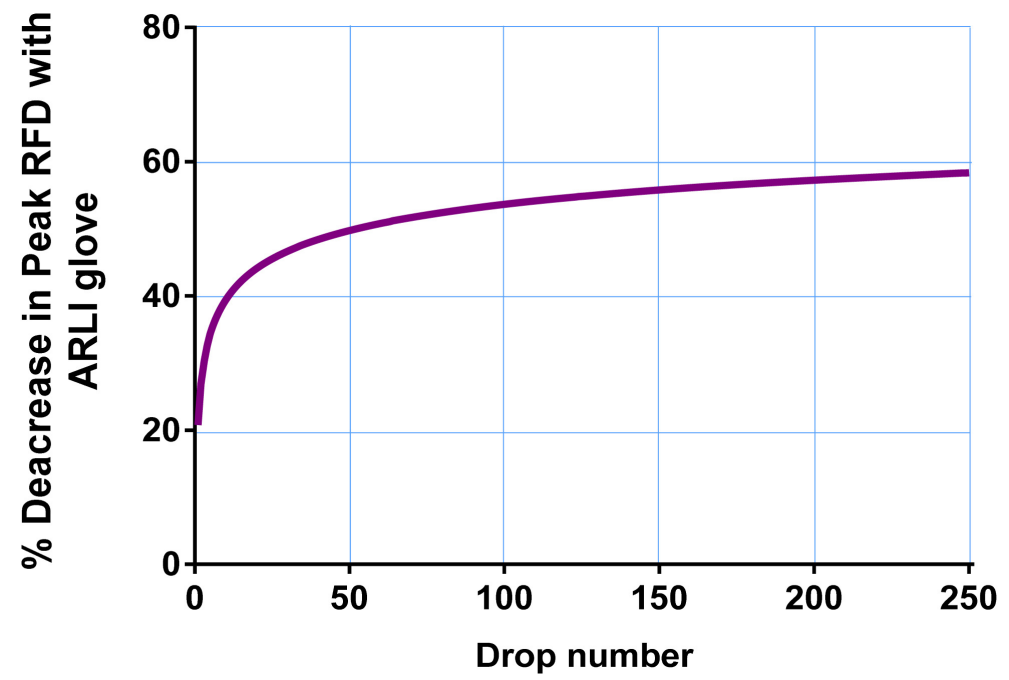

Figure 11. Percentage reduction in peak rate of force development provided by ARLI glove relative to Std $10 \mathrm{oz}$ glove over a series of 250 glove drops on to a force plate from a height of 3 metres, as indicated by application of power regression models derived from real laboratory observations.

plate was consistently below $10 \mathrm{~N}$. For both gloves, the force plate contact time showed a downward trend.

In contrast to the findings for peak impact force and peak rate of force development, variability in the progression of contact time readings was less for the Std $10 \mathrm{oz}$ glove than for the ARLI glove. Indeed, the progression for the Std 10 oz glove was very smooth up to and including Drop 140.

Results of statistical analysis relating to force plate contact time are presented in Table 4. All linear regression models based on logarithmic data had a statistically significant negative slope. One-way ANOVA showed that the magnitude of this slope was significantly larger $(\mathrm{P} \leq 0.0001)$ for the Std $10 \mathrm{oz}$ glove than for 


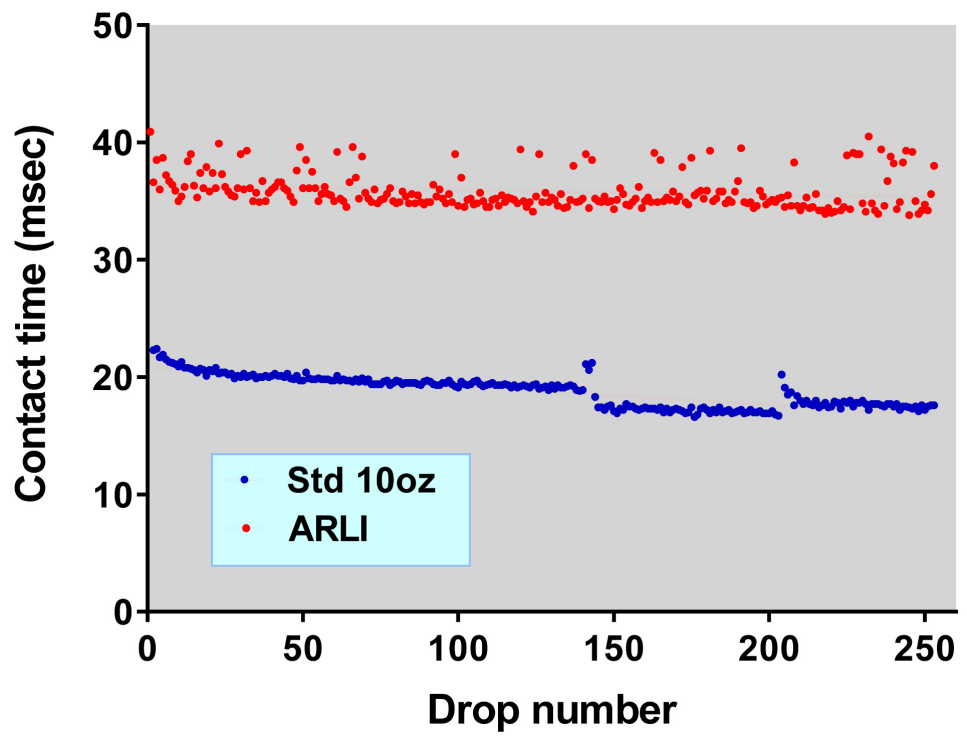

Figure 12. Raw data showing change in contact times between glove and force plate for two different gloves each dropped on to the force plate 253 times from a height of 3 metres.

Table 4. Results of linear regression analysis relating force plate contact time to drop number for two different glove types, with the model for the Std $10 \mathrm{oz}$ glove derived from 139 glove drops, one model for the ARLI glove derived from 137 drops and another model for the ARLI glove derived from 248 drops.

\begin{tabular}{|c|c|c|c|}
\hline & Std $10 \mathrm{oz}(139)$ & ARLI (137) & ARLI (248) \\
\hline $\begin{array}{l}\text { Linear regression equation } \\
\text { based on logarithmic values }\end{array}$ & $\begin{array}{c}Y=(-0.0359 * X)+ \\
1.359\end{array}$ & $\begin{array}{c}Y=(-0.0190 * X)+ \\
1.588\end{array}$ & $\begin{array}{c}Y=(-0.0134 * X)+ \\
1.58\end{array}$ \\
\hline $\mathrm{R}^{2}$ & 0.9418 & 0.2201 & 0.0994 \\
\hline $\begin{array}{l}\text { Probability that true slope is } \\
\text { zero }\end{array}$ & $\mathrm{P}<0.0001$ & $\mathrm{P}<0.0001$ & $\mathrm{P}<0.0001$ \\
\hline Power equation & $Y=22.86^{\star} X^{-0.0359}$ & $Y=38.73 * X^{-0.0190}$ & $Y=38.02 * X^{-0.0134}$ \\
\hline $\begin{array}{l}\text { Standard deviation of } \\
\text { residuals (Sy.x) } \\
\text { for power curve }\end{array}$ & 0.168 & 1.250 & 1.437 \\
\hline $\begin{array}{c}\text { Sy.x as } \% \text { of highest \& lowest } \\
\text { observed values }\end{array}$ & $0.7,0.9$ & $3.1,3.7$ & $3.5,4.3$ \\
\hline
\end{tabular}

the ARLI glove models, which were not statistically different from each other ( $\mathrm{P}$ $=0.2690$ ). For the Std $10 \mathrm{oz}$ glove, over $94 \%$ of the variation in the logarithm of contact time could be explained by progression of drop number. This percentage was much lower for the two ARLI glove models but because the $\mathrm{R}^{2}$ values were significant with an uncertainty equal to or less than 1 in 10,000 calculation of power equations was still considered justified. The standard deviation of differences between raw readings and values determined from the power regression model was less than $1 \%$ of even the lowest raw reading in the case of the Std 10 oz glove, providing a further indication of excellent model fit. The corresponding figures for the ARLI models were in the range of $3.7 \%$ to $4.3 \%$, implying that 
the fit was reasonable.

Curves generated from the power regression equations for contact time appear in Figure 13, which shows that the departure from parallel, while statistically significant, is quite small. The model for the Std $10 \mathrm{oz}$ indicates a reduction in contact time of $1.8 \mathrm{msec}$ from Drop 1 to Drop 10, and a further $2.3 \mathrm{msec}$ from Drop 10 to Drop 250, making a total decrease of $4.1 \mathrm{msec}$. Aggregated values from the two ARLI models show a reduction of $1.4 \mathrm{msec}$ from Drop 1 to Drop 10, and a further $1.9 \mathrm{msec}$ from Drop 10 to Drop 250, yielding a total decrease of $3.3 \mathrm{msec}$. The difference between the two gloves becomes greater when expressed in relative terms, with total decreases in contact time being equivalent to $18.0 \%$ and $8.6 \%$ of the Drop 1 values for the Std 10 oz glove and ARLI gloves respectively.

Figure 14 shows how variation in force plate contact time related to variation in peak impact force for the two glove types. Two separate graphs are included for the Std $10 \mathrm{oz}$ glove-one based on 139 glove drops (the first 140 less one problematic) and the other on 250 drops (253 less three problematics). In both graphs, a strong linear relationship is evident, with reduced contact times associated with increases in peak force. While correlation does not necessarily imply causation, it is pertinent that following the problematic drop 141, which presumably affected the characteristics of the Std $10 \mathrm{oz}$ glove, sudden changes in contact time and peak impact force occurred in almost perfect synchrony, such that when 250 drops of the glove were included in the analysis, more than $96 \%$ of the variance in peak impact force could be explained by variance in contact time. For the ARLI glove, the relationship was of the same direction but, despite reaching statistical significance, it was not nearly as strong, with variance in contact time explaining only $\sim 9 \%$ of the variance in peak force.

Results similar to the above were obtained for the relationship between contact

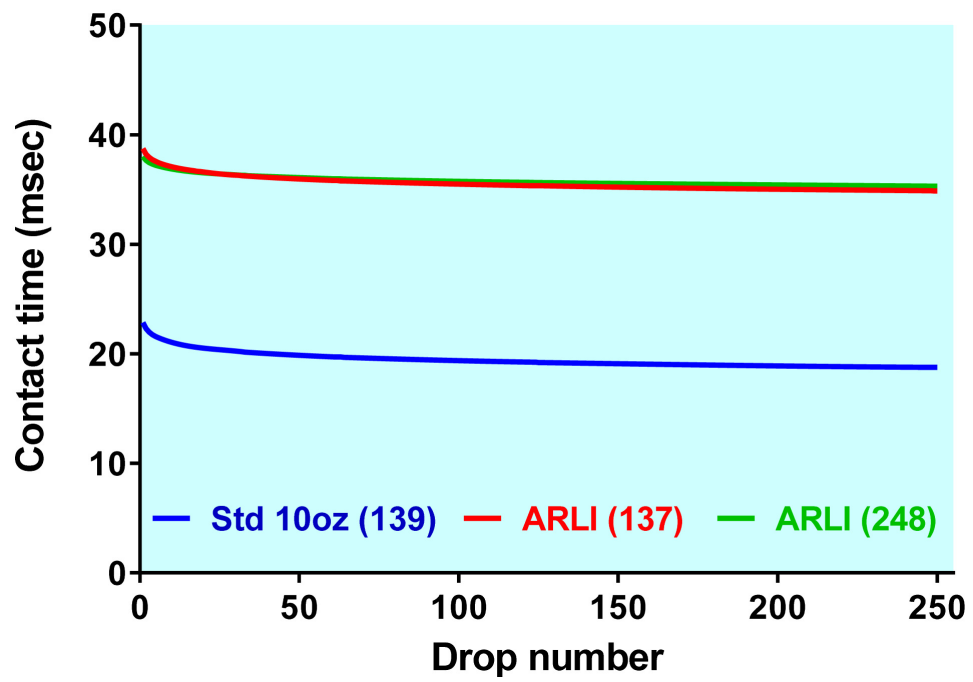

Figure 13. Force plate contact times for Std $10 \mathrm{oz}$ and ARLI gloves, as indicated by regression models derived from 139 valid observations for the Std $10 \mathrm{oz}$ glove, the first 137 valid observations for the ARLI glove, and all 248 valid observations for the ARLI glove. 

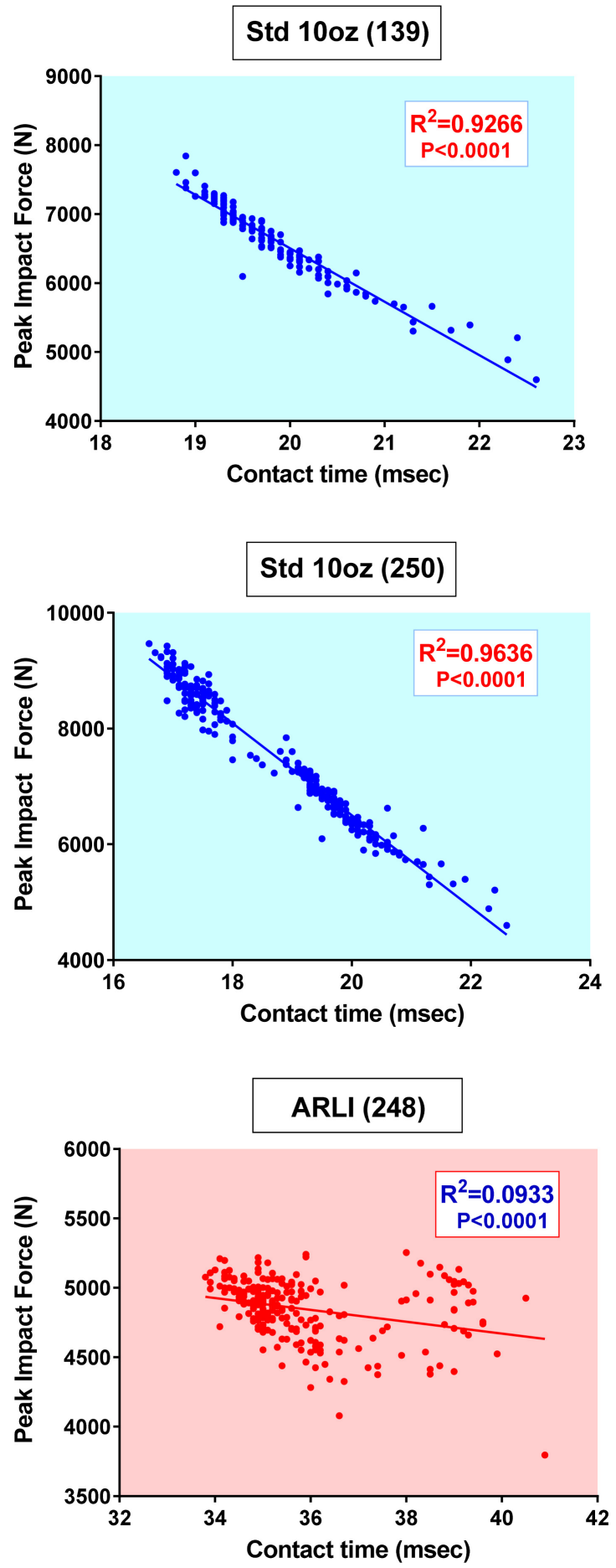

Figure 14. Relationship between force plate contact time and peak impact force for two different glove types. The top panel is based on 139 drops of the Std 10 oz glove, the second panel on 250 drops of that glove, and the bottom panel on 248 drops of the ARLI glove.

time and peak rate of force development, with linear regression analysis incorporating 139 drops of the Std $10 \mathrm{oz}$ glove, 250 drops of that glove and 248 drops of the ARLI glove yielding $\mathrm{R}^{2}$ values of $0.8861,0.9457$ and 0.0885 respectively. 
We wondered whether the lesser predictive value of contact time in the case of the ARLI glove might be due to lower reliability in contact time measurement. It seemed conceivable that "softer" impact produced by that glove could diminish ability to precisely discern points of impact initiation and cessation. Accordingly, we decided that in addition to examining contact time it might be instructive to consider the time from the beginning of force plate contact to the attainment of peak force, since the latter would be likely to have a more definitive end-point.

Figure 15 shows change in the time from glove contact to attainment of peak force as a function of the number of drops for the two glove types. The disruption to readings for the Std $10 \mathrm{oz}$ glove following drop 140 is clear. Readings for the ARLI glove progressed within a proportionally narrower band than was the case for total contact time, particularly after the first 20 glove drops.

Major statistical findings concerning the change in time to peak force are presented in Table 5. The slopes of all three linear regression models based on logarithmic values were negative and significantly different from zero. The negative slope for the Std $10 \mathrm{oz}$ glove was found to be significantly steeper $(\mathrm{P}<0.0001)$ than that for either of the two ARLI glove models, while the slopes for the latter were not significantly different from each other $(P=0.9277)$. For the Std $10 \mathrm{oz}$ glove, almost $85 \%$ of the variance in the logarithm of time to peak force was explicable in terms of the logarithm of drop number. The percentages were lower for the ARLI glove models, but still exceeded $41 \%$ for the model derived from 248 valid readings and $26 \%$ for the model obtained from 137 valid readings. Values provided by power equations generated from the logarithmic models were generally close to observed values, as demonstrated by the fact that the standard deviation of the residuals was between $1.1 \%$ and $1.6 \%$ of the lowest observed value in each instance.

Curves derived from the power equations for time to peak force appear in Figure 16. The equation for the Std $10 \mathrm{oz}$ glove indicated a reduction of $0.7 \mathrm{msec}$

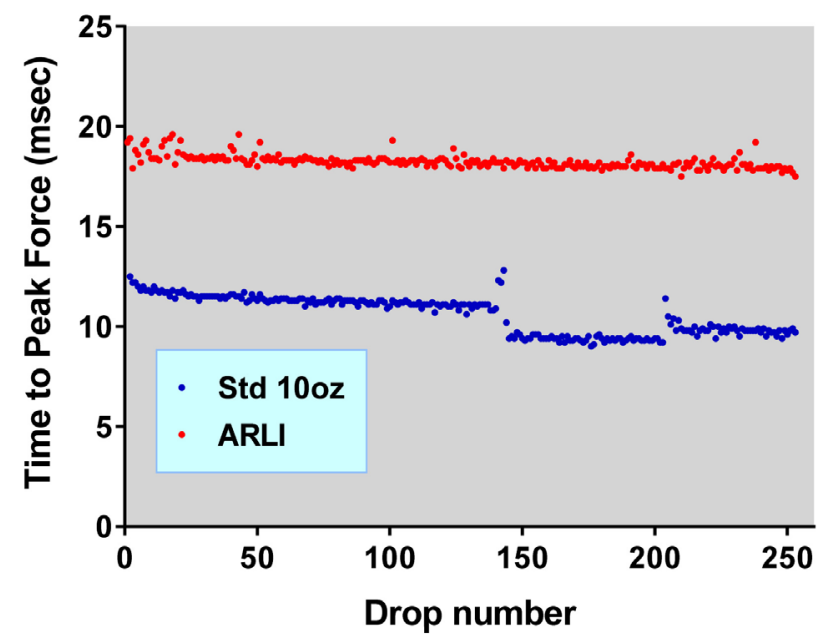

Figure 15. Raw data indicating time from glove contact to peak force for two gloves each dropped 253 times on to a force plate from a height of 3 metres. 
Table 5. Results of linear regression analysis relating time to peak force to drop number for two different glove types, with the curve for the Std $10 \mathrm{oz}$ glove derived from 139 glove drops, one model for the ARLI glove derived from 137 drops and another model for the ARLI glove derived from 248 drops.

\begin{tabular}{cccc}
\hline & Std 10 oz (139) & ARLI (137) & ARLI (248) \\
\hline $\begin{array}{c}\text { Linear regression } \\
\text { equation based on } \\
\text { logarithmic values }\end{array}$ & $Y=\left(-0.0268^{*} X\right)+$ & $Y=(-0.0099 * X)+$ & $Y=\left(-0.0123^{*} X\right)+$ \\
$\mathrm{R}^{2}$ & 1.101 & 1.282 & 1.285 \\
$\begin{array}{c}\text { Probability that true } \\
\text { slope is zero }\end{array}$ & 0.8473 & 0.2646 & 0.4145 \\
$\begin{array}{c}\text { Power equation } \\
\text { Standard deviation of } \\
\text { residuals (Sy.x) } \\
\text { for power curve }\end{array}$ & $Y=12.62 * X^{-0.0268}$ & $Y=19.14 X^{-0.0099}$ & $Y=19.28{ }^{*} X^{-0.0123}$ \\
$\begin{array}{c}\text { Sy.x as \% of highest \& } \\
\text { lowest observed values }\end{array}$ & 0.121 & 0.294 & 0.263 \\
\hline
\end{tabular}

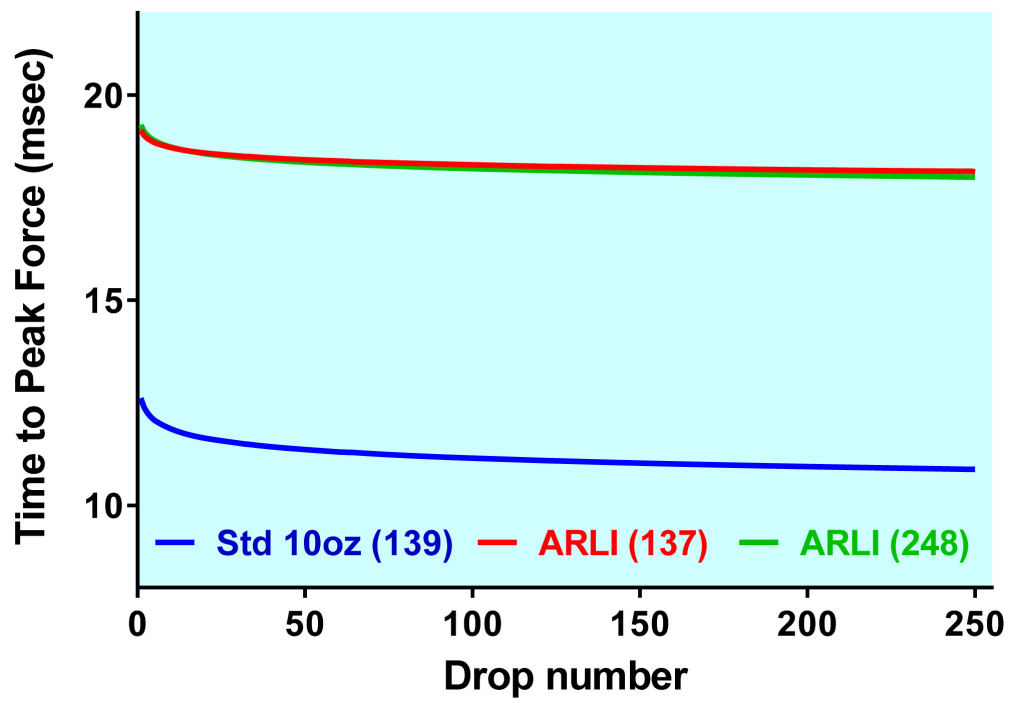

Figure 16. Time from force plate contact to attainment of peak force for Std $10 \mathrm{oz}$ and ARLI gloves, as indicated by regression models derived from 139 valid observations for the Std $10 \mathrm{oz}$ glove, the first 137 valid observations for the ARLI glove, and all 248 valid observations for the ARLI glove.

from Drop 1 to Drop 10, and a further $1.0 \mathrm{msec}$ from Drop 10 to Drop 250, with the total decease therefore being $1.7 \mathrm{msec}$ (13.5\% of the Drop 1 value). Averaging of data from the two ARLI models showed a reduction of $0.5 \mathrm{msec}$ from Drop 1 to Drop 10 and another $0.6 \mathrm{msec}$ from Drop 10 to Drop 250, giving a total decrease of $1.1 \mathrm{msec}$ (5.7\% of the Drop 1 value).

The modelling showed that time to peak force accounted for a higher percentage of total contact time for the Std $10 \mathrm{oz}$ glove than for the ARLI glove $55 \%$ $58 \%$ vs $49 \%-52 \%)$.

The relationship of time to peak force to magnitude of peak force for the two 
glove types is presented in Figure 17. For the Std $10 \mathrm{oz}$ glove, the predictive effect of time to peak force was almost as good as that of total contact time. When 250 drops of this glove (including 111 drops following the problematic Drop
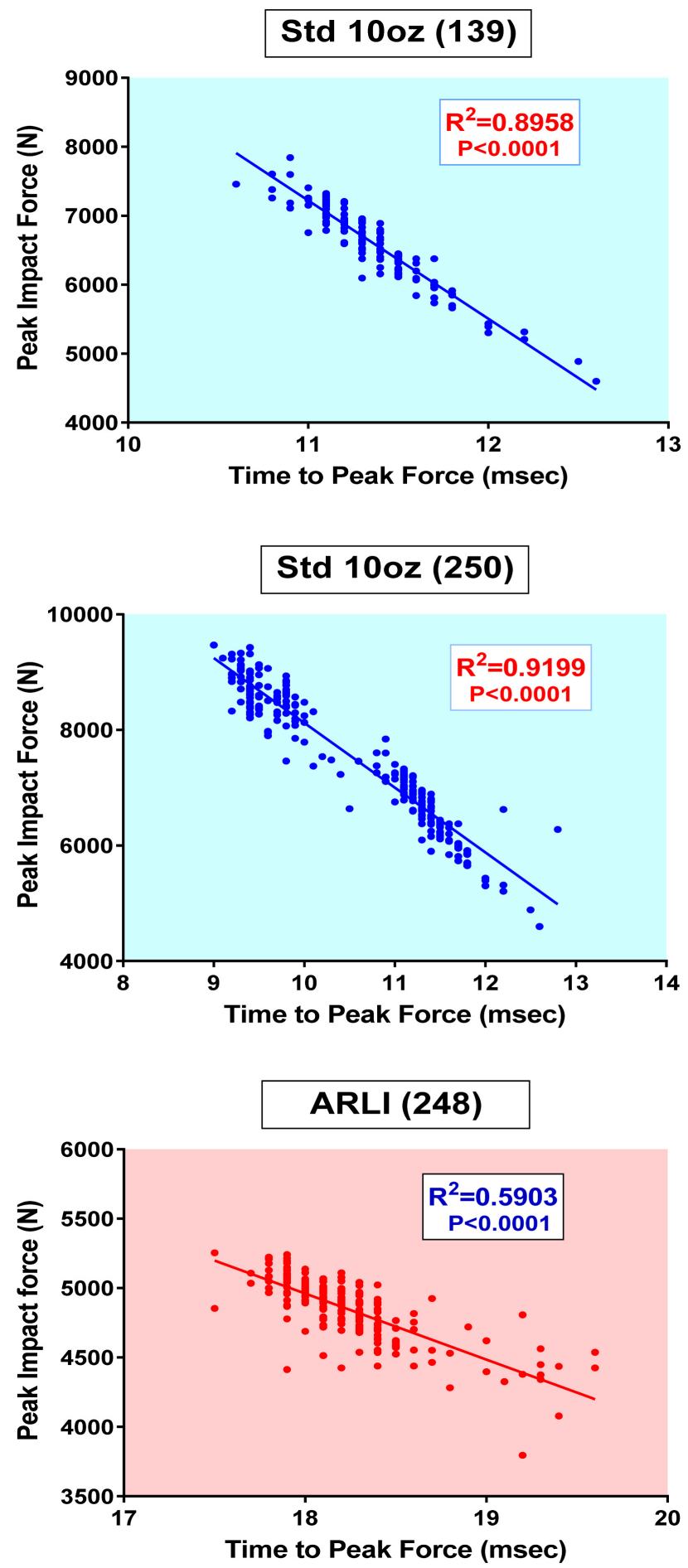

Figure 17. Relationship between time to peak force and magnitude of peak force for two different glove types. The top panel is based on 139 drops of the Std 10 oz glove, the second panel on 250 drops of that glove, and the bottom panel on 248 drops of the ARLI glove. 
141) were included in linear regression analysis, $\sim 92 \%$ of the variance in peak force was explicable by variance in time to peak force. For the ARLI glove, time to peak force was superior to total contact time as a predictor of peak force magnitude, being able to explain $\sim 59 \%$ of the variance.

Time to peak force was also a good a predictor of the instantaneous peak rate of force development, with the $\mathrm{R}^{2}$ value being 0.8815 for the linear regression equation derived from 139 drops of the Std $10 \mathrm{oz}$ glove, 0.9141 for the equation derived from 250 drops of that glove, and 0.5653 for the equation based on 248 drops of the ARLI glove.

To further explore relationships between temporal aspects of collisions and changes in force generation over a long series of repeated glove drops, we examined individual force-time curves for both glove types. Observed curves for drops 10, 50, 100, 140, 150, 200 and 250 in the laboratory experiments are presented in Figure 18. For the ARLI glove, the curves clearly consisted of a slow phase during which they essentially traced over one another, and a fast phase during which some separation as a function of drop number eventually became evident.
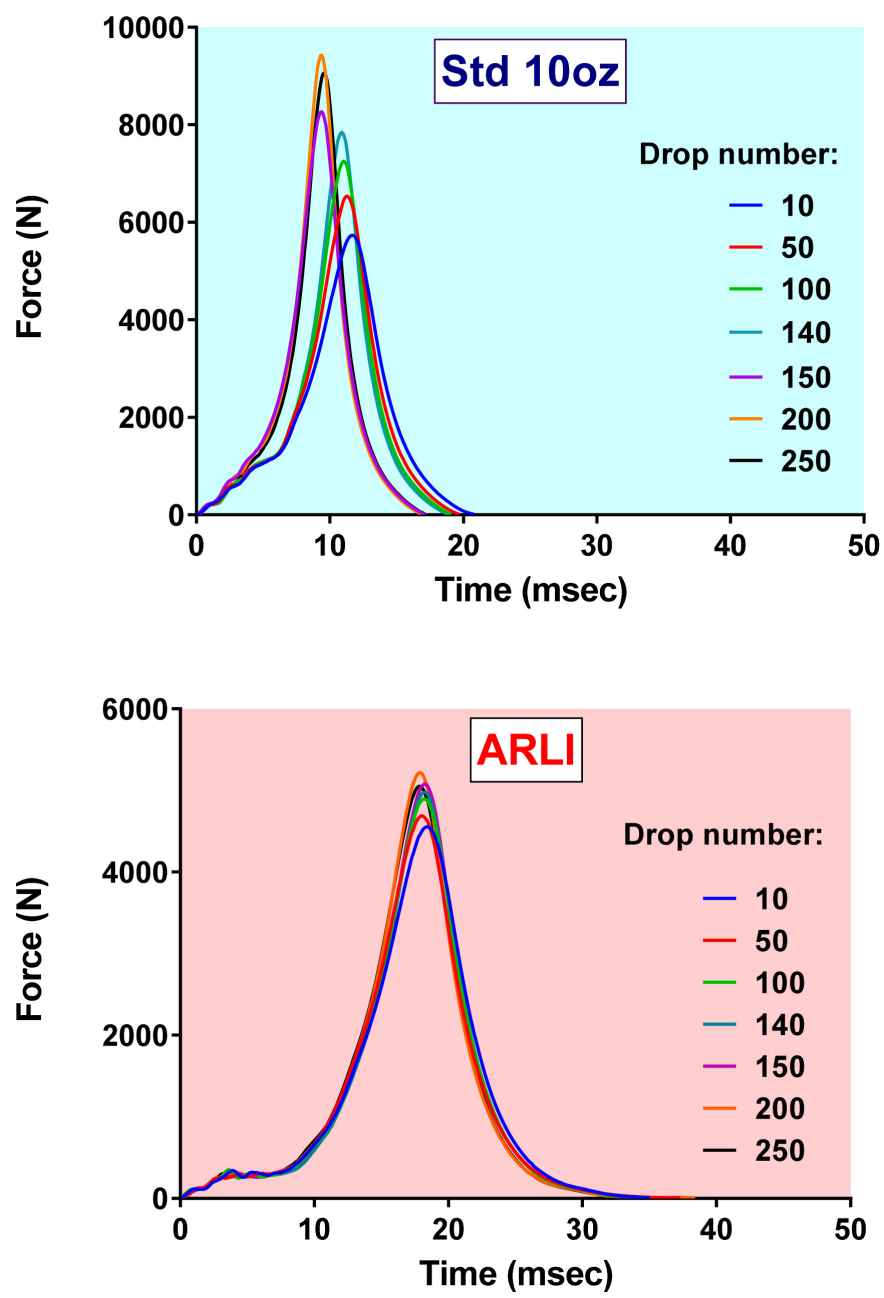

Figure 18. Force-time curves for Std $10 \mathrm{oz}$ and ARLI gloves as a function of number of drops. Note that the scales on the Y-axis differ between the two panels. 
This was true also for the Std 10 oz glove up to and including Drop 140. The problematic Drop 141 seemed to cause the slow phase of the curve to become shorter and less distinct, making the curve for Drop 150 quite different from the earlier drops depicted in Figure 18. Drops 150, 200 and 250, however, displayed substantial similarity, varying primarily just in height.

Figure 19 provides data for Drops 10, 50, 100, 140, 150, 200 and 250 with respect to time course of change in rate of force development. Key features resemble those observed for impact force. For the Std $10 \mathrm{oz}$ glove, there was no early separation of curves up to and including Drop 140. Earlier separation did occur in the aftermath of the probably glove-altering Drop 141. The curves for Drops $10,50,100$ and 140 of the Std $10 \mathrm{oz}$ glove essentially traced over one another for the first 6 - $7 \mathrm{msec}$. In the case of the ARLI glove, changes in rate of force development as a function of drop number were not apparent until $\sim 13 \mathrm{msec}$.

The finding that the ARLI glove, when compared to the Std 10 oz glove, produced lower peak forces and peak rates of force development, increased contact

\section{Std $100 z$}

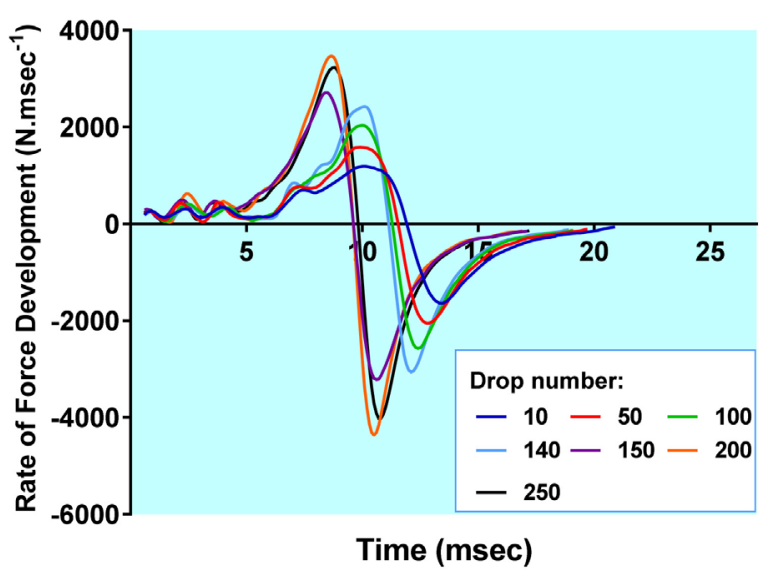

ARLI

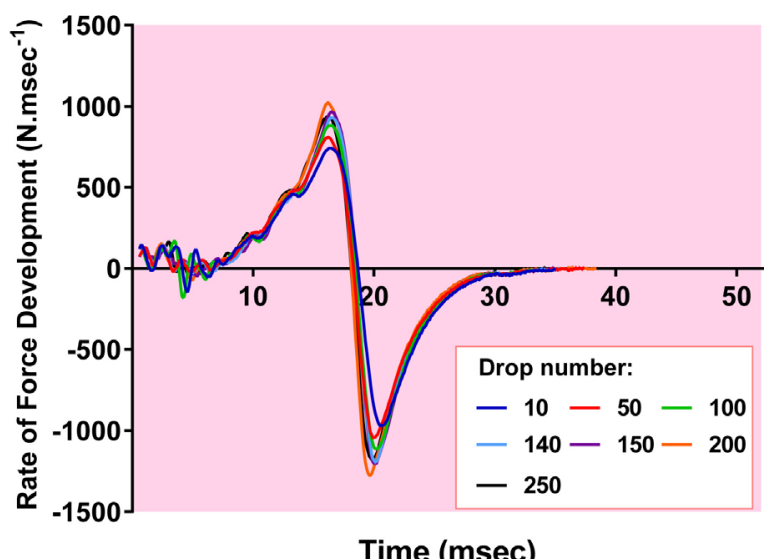

Figure 19. Curves showing relationship of rate of force development to time over a long series of glove drops for Std $10 \mathrm{oz}$ and ARLI gloves. Note that the scales on both axes differ between the two panels. 
time with the target and the time to peak force, and diminished drift in the various parameters over a long series of repeated glove drops, was not due to reduction of the impulse of impact. We estimated the latter by using the trapezoid method to calculate area under the force-time curve (AUC) for every glove drop.

The results are shown in Figure 20. AUC was lower for the Std $10 \mathrm{oz}$ glove than the ARLI glove, probably because the former was lower in mass, but rose more rapidly with repeated glove drops. Change in the progression of AUC for the Std 10 oz glove after the problematic Drop 141 was detectable but less dramatic than that observed for other impact parameters.

Outcomes of statistical analysis of the AUC data appear in Table 6. For the Std $10 \mathrm{oz}$ glove, $\sim 71 \%$ of the variance in the logarithm of AUC was explicable in terms of change in the logarithm of drop number. For the ARLI glove models this figure was in the range of $30-32 \%$. For each of the logarithmic linear regression models, the relationship between predicted and observed AUC values was statistically significant. The slope of the line for the Std $10 \mathrm{oz}$ glove was significantly larger than that for either of the ARLI models $(P<0.0001)$, while no statistical difference between the slopes for the two ARLI models could be discerned $(P=0.9794)$. Power equations generated from the logarithmic linear models provided a good fit with laboratory data, as evidenced by the fact that the standard deviation of the residuals was never more than $0.5 \%$ of the lowest observed value.

Curves developed from the AUC power equations are presented in Figure 21. The upward trend of the curves is notable given that the impact energy resulting from dropping an object of specific mass from a controlled height is theoretically constant.

One possible reason for the rise in AUC with repeated glove drops is a gradual reduction in the ability of the colliding objects to store some of the impact energy. Such storage could occur, for example, through deformation of a glove and/or the EVA mat covering the force plate. With successive glove drops, there

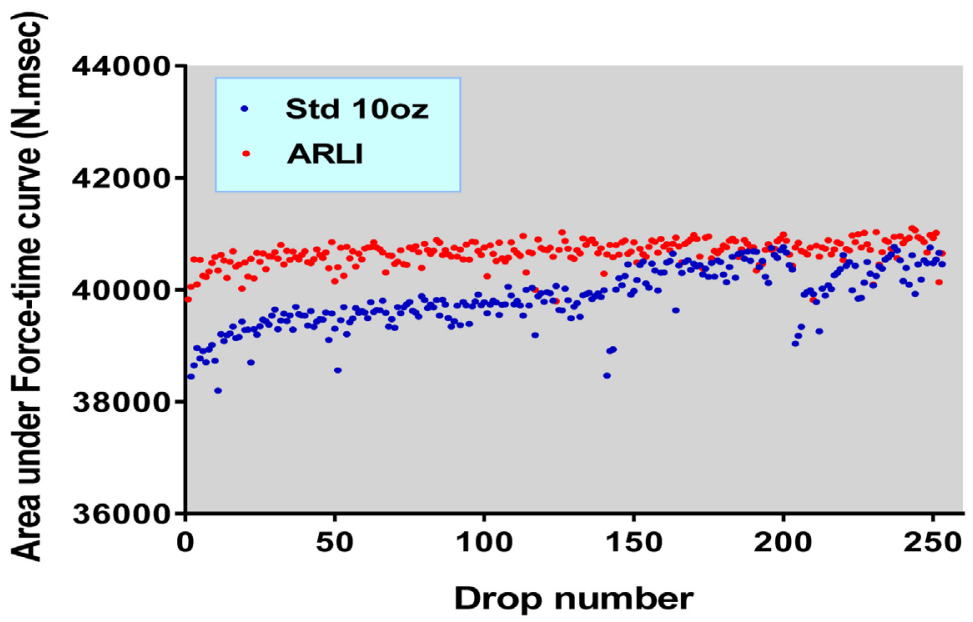

Figure 20. Raw data indicating change in area under the force-time curve for two different gloves over a series of 253 drops on to a force plate from a height of 3 metres. 
Table 6. Results of linear regression analysis relating area under the force-time curve to number of glove drops for two different glove types, with the model for the Std $10 \mathrm{oz}$ glove derived from 139 glove drops, one model for the ARLI glove derived from 137 drops, and another model for the ARLI glove derived from 248 drops.

\begin{tabular}{|c|c|c|c|}
\hline & Std $10 \mathrm{oz}(139)$ & ARLI (137) & ARLI (248) \\
\hline $\begin{array}{l}\text { Linear regression } \\
\text { equation based on } \\
\text { logarithmic values }\end{array}$ & $\begin{array}{c}Y=\left(0.008029^{*} X\right)+ \\
4.583\end{array}$ & $Y=\left(0.00315^{*} X\right)+4.603$ & $\begin{array}{c}Y=(0.003053 * X)+ \\
4.603\end{array}$ \\
\hline $\mathrm{R}^{2}$ & 0.7121 & 0.3241 & 0.2990 \\
\hline $\begin{array}{c}\text { Probability that true } \\
\text { slope is zero }\end{array}$ & $\mathrm{P}<0.0001$ & $\mathrm{P}<0.0001$ & $\mathrm{P}<0.0001$ \\
\hline Power equation & $Y=38282^{\star} X^{0.0080}$ & $Y=40087^{\star} X^{0.0032}$ & $Y=40087^{\star} X^{0.0031}$ \\
\hline $\begin{array}{l}\text { Standard deviation of } \\
\text { residuals (Sy.x) } \\
\text { for power curve }\end{array}$ & 189.1 & 174.6 & 183.4 \\
\hline $\begin{array}{l}\text { Sy.x as \% of highest \& } \\
\text { lowest observed values }\end{array}$ & $0.45,0.50$ & $0.43,0.44$ & $0.45,0.46$ \\
\hline
\end{tabular}

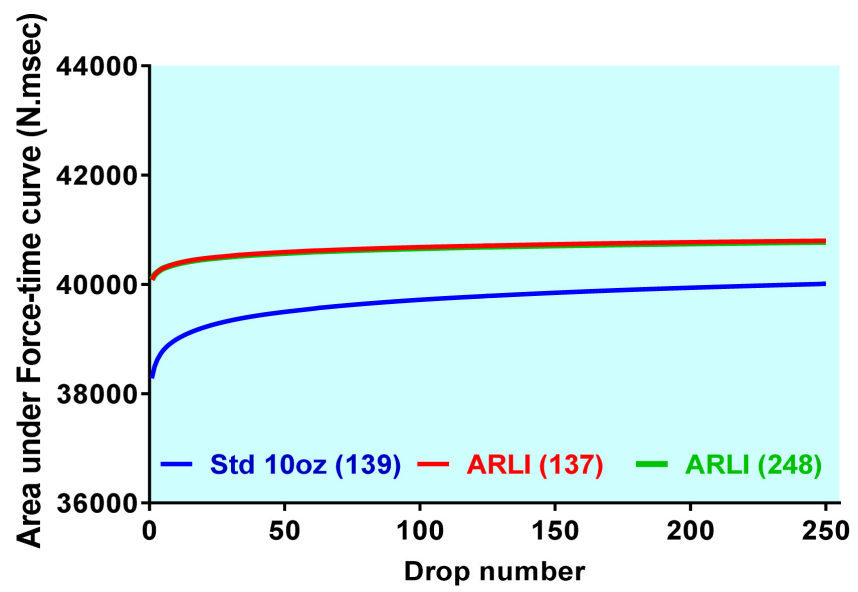

Figure 21. Area under the force-time curve for Std $10 \mathrm{oz}$ and ARLI gloves, as indicated by regression models derived from 139 valid observations for the Std $10 \mathrm{oz}$ glove, the first 137 valid observations for the ARLI glove, and all 248 valid observations for the ARLI glove.

could be diminishing capacity for further deformation, causing more of the impact energy to be transferred to the force plate. This could affect a range of impact metrics, including peak force.

Figure 22 shows relationship between AUC and peak force for the two different glove types included in our experiment. For the Std $10 \mathrm{oz}$ glove, the relationship was strong, with a linear regression model derived from 250 points able to explain almost $84 \%$ of the variance in peak force based on variance in AUC. The corresponding figure for the ARLI glove was markedly lower at $\sim 47 \%$, although the association between peak force and AUC was still statistically significant.

Comparable results were obtained for the relationship of AUC to peak rate of 


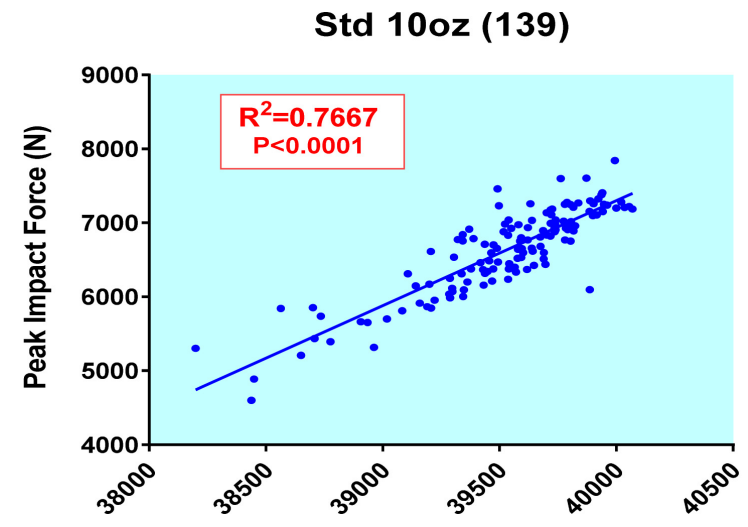

Area under Force-Time curve (N.msec)

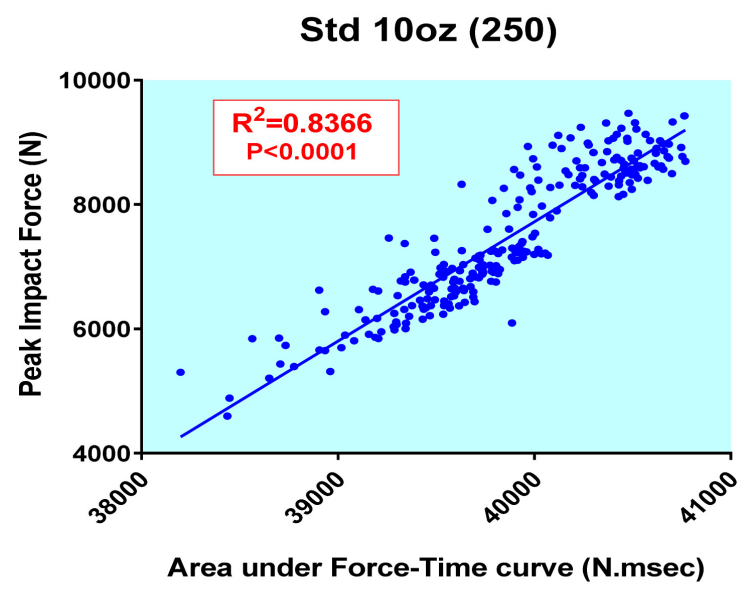

ARLI (248)

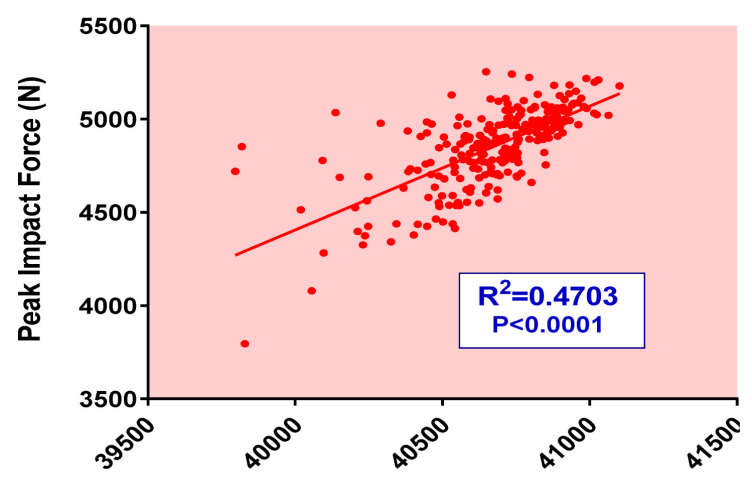

Area under Force-Time curve (N.msec)

Figure 22. Relationship between area-under the force-time curve and peak impact force for two different glove types. The top panel is based on 139 drops of the Std 10 oz glove, the second panel on 250 drops of that glove, and the bottom panel on 248 drops of the ARLI glove.

force development, but here the relationship was better described by a power regression model than by linear regression. The power models yielded $\mathrm{R}^{2}$ values of 
$0.7616,0.8298$ and 0.4395 for 139 drops of the Std $10 \mathrm{oz}$ glove, 250 drops of the Std $10 \mathrm{oz}$ glove and 248 drops of the ARLI glove respectively. In each case, the probability of a zero relationship was less than 0.0001 .

AUC, force plate contact time and time from initial force plate contact to attainment of peak force could not be considered independent predictors of peak force or peak rate of force development since they co-varied, as shown in Table 7. The extent of co-variation was much less for the ARLI glove than for the Std $10 \mathrm{oz}$ glove.

Overall, force plate contact time was the best single predictor of peak force and peak rate of force development for the Std $10 \mathrm{oz}$ glove, while time from initial force plate contact to attainment of peak force was the best predictor for the ARLI glove. The performance of the Std $10 \mathrm{oz}$ glove could be predicted with greater accuracy.

Figure 23 shows what happened to peak impact force when, after 253 drops of the ARLI glove, the EVA 75 mat covering the force plate was replaced with a new one, and the glove was then dropped a further 10 times. We reasoned that if drift in peak force over the 253 drops was wholly due to impact-induced changes

Table 7. Matrix showing inter-relationships between selected impact metrics. $\mathrm{R}^{2}$ values determined through linear regression are given together with the associated probability that the true relationship could be zero. The $\mathrm{R}^{2}$ values are based on 250 observations for the Std 10 oz glove and 248 for the ARLI glove.

\begin{tabular}{ccc}
\hline & Std $10 \mathrm{oz}$ & ARLI \\
\hline AUC vs Contact Time & $0.8153(\mathrm{P}<0.0001)$ & $0.0259(\mathrm{P}=0.0112)$ \\
AUC vs Time to Peak Force & $0.7297(\mathrm{P}<0.0001)$ & $0.2082(\mathrm{P}<0.0001)$ \\
Contact Time vs Time to Peak Force & $0.9638(\mathrm{P}<0.0001)$ & $0.0612(\mathrm{P}<0.0001)$ \\
\hline
\end{tabular}

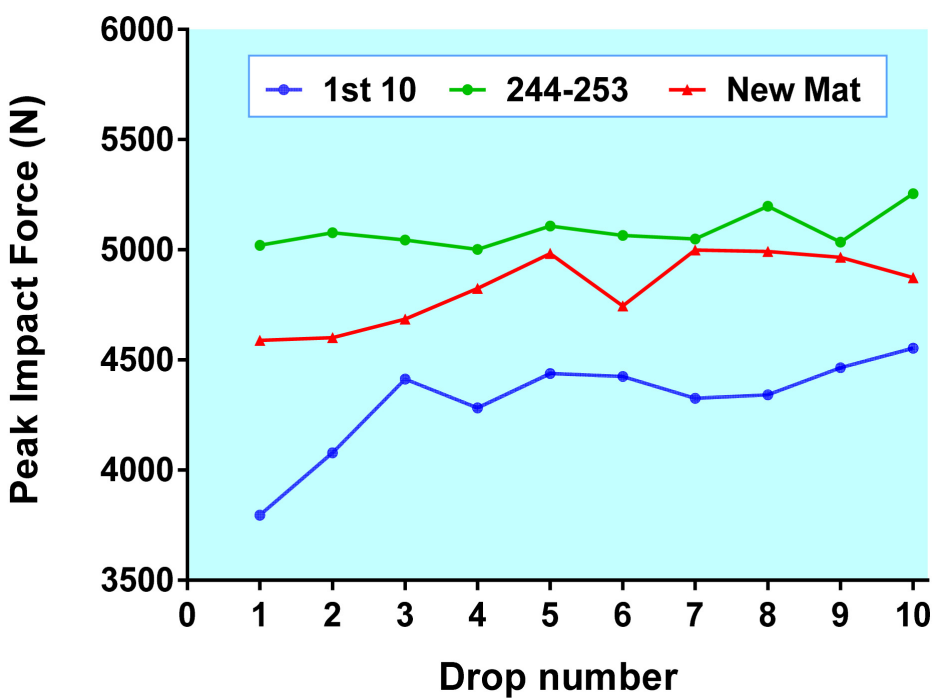

Figure 23. Effect of replacing the EVA 75 mat covering the force plate on peak impact forces measured when the ARLI glove was dropped on to the plate from a height of 3 metres. $1^{\text {st }} 10=$ first 10 drops of the 253 -drop sequence, $244-253=$ last 10 drops of that sequence, New Mat = 10 drops performed after a new EVA 75 mat was introduced. 
in the properties of the mat, introduction of a new mat should produce readings resembling those obtained at the outset of the 253-drop series. Conversely, if drift in peak force was entirely attributable to changes in glove properties, readings following replacement of the mat would be much the same as those recorded for the last few of the 253 drops. The data revealed that introduction of the new mat reduced the mean peak forces for the following 10 drops to a level that was $\sim 66 \%$ of the way between the means for the first and last 10 of the 253 drops. If only the highest five values for each 10-drop sequence were considered, this figure increased to $74 \%$. It therefore seemed that $26 \%-34 \%$ of the upward drift in peak force during the long sequence of impacts was due to mat alteration, with $66 \%-74 \%$ due to glove alteration.

In addition to the reduction in the magnitude of peak force after mat replacement, the pattern of change in peak force over the course of the 10 drops was affected. For the first 10-drop sub-block of the 253-drop series, the coefficient of variation was $5.15 \%$, reflecting the fact that peak forces rose quite sharply at the outset. For the next 24 sub-blocks the coefficient of variation averaged $1.8 \%$ with a standard deviation of $0.51 \%$. The 10 drops following mat replacement yielded a coefficient of variation that, at 3.35\%, was $3.01 \%$ standard deviations above that average and the second highest value recorded in the whole day of testing. The probability that we could have obtained this result if there was no real influence of mat replacement is less than three in a thousand.

At the end of each of the two days of our experiment, we carried out a visual examination of the glove that had undergone testing. We detected no evidence of change to the ARLI glove. As shown in Figure 24, the Std $10 \mathrm{oz}$ glove padding showed some sign of deformation in the area close to the wrist.

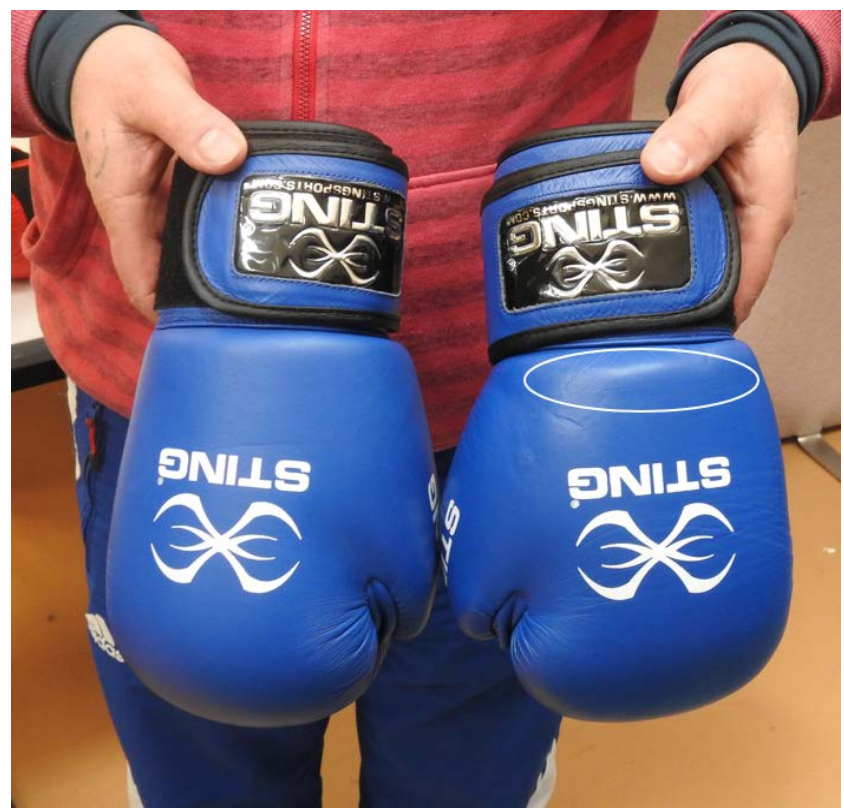

Figure 24. Deformation near wrist region of Std $10 \mathrm{oz}$ glove after 253 drops on to a force plate. The area of deformation is indicated by the white elipse. A glove with which the dropped glove formed a pair is shown for comparison. 


\section{Discussion}

We set out to quantify the progression of impact variables for Std $10 \mathrm{oz}$ and ARLI boxing gloves over a series of 250 drops on to a force plate from a height of 3 metres. In the case of the ARLI glove, we were able to analyse 248 data points to develop statistical models. Since these data points spanned 253 glove drops (of which five were excluded for technical reasons), the resultant models were of an interpolative nature. By contrast, a technical problem that occurred on the $141^{\text {st }}$ drop of the Std $10 \mathrm{oz}$ glove had a lasting effect on subsequent impact dynamics and meant that only the first 140 drops (one of which was technically invalid) could be used for model development. Quantification of the effects of 250 glove drops therefore depended on extrapolation of trends observed over a lesser number of drops. Through development of two different models for the ARLI glove, one based on 248 glove drops and the other based on the first 140, we were able to demonstrate that the interpolative and extrapolative approaches produced essentially identical results for all impact variables examined. This made it clear that for the ARLI glove 140 observations were sufficient to enable establishment of models that could be accurately extrapolated out to 250 glove drops. It seems reasonable to expect that the same would be true for the Std 10 $\mathrm{oz}$ glove and that our findings concerning changes in impact variables for the two glove types over the course of 250 drops are realistic.

A key finding of our research is that for both glove types all measured impact variables showed progressive change and did not reach a plateau even after as many as 250 drops. Also important is the fact that the rate of change in the variables over the course of 250 drops was always greater for the Std 10 oz glove than the ARLI glove. Our previous studies have shown that, compared to a Std $10 \mathrm{oz}$ glove, the ARLI glove provides acute reduction of the peak force and peak rate of force development associated with standardized impacts of a magnitude that can be encountered by boxers. This information is now supplemented by the observation that under our experimental conditions it also damps cumulative change in these parameters over a long series of ostensibly identical impacts. An implication of the new observation is that the relative degree of protection provided by the ARLI glove becomes greater as the number of impacts increases.

Only a few other studies have examined change in impact damping performance of boxing gloves over a long series of impacts. In 1985, Smith and Hamill [10] reported a study in which they dropped a conventional boxing glove on to a force plate 50 times from a height that produced a pre-impact glove velocity of $2.0 \mathrm{~m} \cdot \mathrm{sec}^{-1}$. Data were recorded for Drops 1 and 5, and for every fifth drop thereafter. The peak impact force increased from $1484 \mathrm{~N}$ at the outset to $2914 \mathrm{~N}$ at the end, a rise of $96 \%$. Much of the change occurred early in the series, with the peak force already over $2150 \mathrm{~N}$ by Drop 5 and over $2450 \mathrm{~N}$ by Drop 10. There were smaller rises up to Drop 35, after which the readings stabilized. The time from initial force plate contact to attainment of peak force decreased from 19 msec on Drop 1 to $15 \mathrm{msec}$ on Drop 5 and $14 \mathrm{msec}$ on Drop 15, before remain- 
ing constant for the rest of the series. The area under the force-time curve increased sharply over the first 20 drops. It then fluctuated in an inconsistent manner but was always higher than the value recorded for Drop 1. Overall, the findings were qualitatively similar to those presented in this paper. Smith and Hamill [10] considered that the increase in peak force over the series was likely due to the decreased glove contact time caused by compression of the glove padding. They saw distribution of the impulse over a shorter contact time as the reason for the higher forces. The composition of the glove padding (a layer of hair sandwiched between two layers of open cell foam contained within a leather sheath) was regarded as sub-optimal since a karate glove with customised molded foam padding demonstrated a much smaller (27\%) increase in peak force across a series of 50 drops. Over recent years, there has been substantial change in the manufacture of boxing gloves, with a range of new materials employed [11] [12]. This has produced a need for research akin to that conducted by Smith and Hamill [10] but entailing evaluation of contemporary gloves.

Lee and McGill [11] used a mechanized device to deliver 10,000 impacts of a conventional $16 \mathrm{oz}$ glove-of the type typically used by boxers for sparring [13] - to a "pancake" force transducer. The impacts were delivered at a rate of one every 1.8 seconds for 5 hours. Force-time characteristics were sampled from 20 impacts at the outset and 20 at the end of each 30-minute period. Data from the 20 impacts were averaged to produce representative force-time curves for each sampling point. The mean peak force was $532 \mathrm{~N}$ at the start of the trial and $747 \mathrm{~N}$ at its end, with the increase therefore amounting to $\sim 40 \%$. Most of the increase took place over the first 2000 impacts, after which the peak impact force already exceeded $700 \mathrm{~N}$. The upward drift in peak force was associated with progressive reductions in contact time and the time to peak force, with the magnitude of shifts following a similar course. Although the peak forces were quite low compared to those reportedly generated by boxers [2] [14] [15] [16] [17] [18], the glove showed visible signs of wear and material deterioration after $\sim 2000$ impacts. It is interesting that its performance then exhibited very little further decrement over the course of another 8000 impacts. The early rise in peak force was ascribed to a "breaking in" period characterised by some degradation of padding materials, after which performance became relatively consistent. It was suggested that the breaking in period was probably characterised by increasing glove stiffness resulting from deformation, with the increased stiffness resulting in less energy loss upon impact and therefore greater peak force.

Recently, Chadli et al. [12] carried out a cross-sectional study of the effects of numerous impacts on the performance of boxing gloves by comparing three new gloves with three that had been extensively used by elite boxers. All the gloves were of the conventional type and had been manufactured to meet a specification that they should have a mass of $10 \mathrm{oz}$. A rotary mechanism incorporating torsion springs was employed to deliver nine impacts of each glove to a target that had lower inertial mass than the striking device and therefore moved away 
from it shortly after contact. The nine impacts were arranged into three sets of three with impact energy levels of 4,18 and $44 \mathrm{~J}$ to simulate punches of different magnitudes. At each impact energy level, peak angular velocity and peak acceleration of the target were substantially greater for the used gloves than for the new ones. Calculated peak impact forces were 128, 540 and $1540 \mathrm{~N}$ for the best-performed new glove, compared to 589, 2060 and $3960 \mathrm{~N}$ for the worst-performed used glove. The latter values were therefore 2.6 - 4.6 times greater than the former. At the low and medium impact energy levels, the new gloves compressed much less than the used gloves, but at the highest energy level, the difference in compression was slight. Consequently, the much-reduced impact damping effects of the used gloves at the highest impact energy level could not be attributed to greater glove compression. Instead, the findings were seen to imply that the foam padding of the used gloves had undergone significant chemical and physical alteration. It can be imagined that repeated collisions could damage the walls of the cells that constitute foam structures, thereby changing the properties of the foam and making it subject to more rapid compression. The time shift might be more important than the extent of maximum compression in explaining deterioration in the protective performance of a glove as a function of repeated impacts.

Our current study augments the work of preceding researchers in several ways. It represents the first evaluation of the performance of a pneumatic boxing glove over a long series of impacts. It also incorporates use of much higher levels of impact energy than has characterized any of the prior research into effects of numerous impacts on glove performance. The previous highest was the $44 \mathrm{~J}$ employed by Chadli et al. [12], who produced that level by combining a glove velocity of $\sim 6.4 \mathrm{~m} \cdot \mathrm{sec}^{-1}$ and a striker mass of $\sim 2.0 \mathrm{~kg}$. We used a glove drop height of 3 metres to generate a pre-impact glove velocity of $\sim 7.6 \mathrm{~m} \cdot \mathrm{sec}^{-1}$. With an effective impact mass of $\sim 3.3 \mathrm{~kg}$, our impact energy level was therefore $\sim 99 \mathrm{~J}$. Walilko et al. [2] reported that for seven elite boxers who delivered maximal straight punches to the head of a Hybrid III manikin the peak pre-impact glove velocity averaged $9.14 \mathrm{~m} \cdot \mathrm{sec}^{-1}$ and the effective mass averaged $2.9 \mathrm{~kg}$. This equates to an impact energy level of $121 \mathrm{~J}$. Hooked punches, however, have been found to produce greater pre-impact velocities, with average readings of $\sim 11.0 \mathrm{~m} \cdot \mathrm{sec}^{-1}$ reported in two different studies [19] [20]. Even if it is assumed that hooked punches have only the same effective mass as straight punches, it appears that impact energy levels as high as $176 \mathrm{~J}$ are realistic. By comparison, the level generated in our experiment can be considered moderate.

The impact forces to which gloves are subject are influenced, however, not just by the impact energy level but also by the target characteristics. Under the conditions of our experiment, the peak impact forces for the Std $10 \mathrm{oz}$ glove over the first five drops were in the range of 4500 to $5400 \mathrm{~N}$. In an earlier paper [1], we summarized available data on the peak impact forces produced by boxers and noted that values in the range of $4000-8000 \mathrm{~N}$ have been recorded in studies 
involving delivery of punches to the heads of crash test manikins designed for maximum biofidelity [2] [14]. Additionally, research involving the use of instrumented gloves during six professional boxing matches showed that while the great majority of peak impact forces were below $2000 \mathrm{~N}$ values exceeding $5000 \mathrm{~N}$ did occur [15]. On this basis it is evident that our study entailed assessment of change in glove performance with repeated heavy impacts whereas previous research (where the initial peak forces varied from 532 to $1500 \mathrm{~N}$ ) was focused on much lighter impacts.

An interesting finding of our research was that upward drift in peak impact force over a series of 253 glove drops was apparently not wholly due to alteration of glove properties, but also reflected impact-induced alteration of the target. To protect our force plate from risk of damage caused by high impact forces, we covered it with a $25 \mathrm{~mm}$ thick mat consisting of a closed cell, thermoplastic copolymer of ethylene and vinyl acetate. This material is recognised as well-suited to vibration and impact absorption, and as flexible, resilient and able to recover quickly from compression [21]. We therefore considered it ideal for our purpose. Nevertheless, when we replaced a mat that had received 253 glove drops with a new one of the same composition and then performed another 10 drops with the same ARLI glove, we observed an immediate reduction in peak impact forces, to an extent suggesting that one-quarter to one-third of the change that had occurred over the course of the 253 drops was likely attributable to target modification. The actual effect might have been somewhat larger or smaller, since manufacturing variations could have caused a small difference in the baseline properties of our two mats, but the fact that mat replacement shifted not just peak forces but also the pattern of their rise over 10 glove drops toward those that were initially observed with the original mat strongly supports the inference that the properties of the latter had undergone some alteration.

We did not conduct a corresponding mat change experiment following 253 drops of the Std $10 \mathrm{oz}$ glove, because of a potential confounding effect of changes in impact dynamics that occurred following Drop 141. Consequently, we cannot exclude the possibility that the proportional effect of target modification on the upward drift in peak impact force for this glove was somewhat different from that seen with the ARLI glove. A larger effect, however, could only have resulted from greater target alteration, an outcome which would still serve to emphasise the ability of the ARLI glove to provide superior target protection in the context of repeated impacts.

It is possible that target modification was associated with storage of potential energy in the mat, with scope for additional storage lessening as the series of drops progressed, thereby accounting for the gradual upward trends in the impulse of impact (as indicated by area under the force-time curve) that occurred with both the ARLI and Std 10 oz gloves. Greater mat compression due to higher impact forces produced by the Std $10 \mathrm{oz}$ glove may have increased the return of potential energy to kinetic energy during breaks between blocks of glove drops, 
thereby contributing to more substantial recovery of that glove between blocks of glove drops, particularly in the long break of more than 70 minutes between Blocks 4 and 5. If this was the case, however, it would be necessary to surmise that the mat was less resistant to recompression following recovery, since peak impact force and peak rate of force development regained quite high levels within the first 10 drops of Block 5 .

Our data are consistent with the notion that the time over which a change in target momentum is distributed is a principal determinant of peak impact force. For the Std $10 \mathrm{oz}$ glove, primacy of this mechanism is strongly suggested by the very high inverse correlation between force plate contact time and peak force $\left(\mathrm{R}^{2}>0.96\right.$ for 250 glove drops). Although the correlation was much lower for the ARLI glove, this might have been due to noise in the contact time data resulting from an effect of slower rise and decline in forces making the points of contact initiation and release less distinct. Such an explanation is supported by the fact that when time to peak force was used in place of contact time as a descriptor of the temporal nature of ARLI glove impacts, thus providing a more precisely identifiable endpoint, the correlation with peak force was substantially improved. Even so, the observation that the $\mathrm{R}^{2}$ value was still only 0.59 offers grounds for conjecture that, for the ARLI glove, a variable other than contact time might also have exerted a major influence on peak force. It is conceivable that in the case of the Std $10 \mathrm{oz}$ glove, progressive increases in peak force may have been due very largely to reduction in time taken to reach a given level of glove compression and stiffness limited by the material properties of the foam padding, while the pneumatic impact-damping mechanism of the ARLI glove allowed a gradual increase in glove stiffness to take place concomitant with decrease in contact time. It can be imagined that the ARLI glove eventually could become dynamically stiffer during impact in concert with a need for more rapid expulsion of air from its bladder through a fixed aperture, a situation obviously not applying to the Std $10 \mathrm{oz}$ glove.

We can only speculate on what might have happened to the Std $10 \mathrm{oz}$ glove in consequence of its off-target landing on Drop 141. As can be discerned from Figure 2 and Figure 12, the two immediately following drops produced considerably lower peak force measurements and longer contact times compared to Drop 140. Then, after a short break, markedly elevated peak force readings and reduced contact times were observed, with the force-time curve shifted decidedly leftward (see Figure 18). These changes persisted for $\sim 60$ drops, before a 73-minute break between Blocks 4 and 5 of the experimental sequence was associated with some recovery, although force-time curves generally remained well to the left of those recorded for the first 140 drops. To us, the most plausible explanation for this pattern is that:

1) The off-target landing caused a marked change in both the shape of the glove and the resistance of its padding to compression.

2) The altered shape caused an increase in the contact surface area of the fol- 
lowing two impacts, with the distribution of the impact energy over this larger area reducing peak forces.

3) During a break of 4.5 minutes before commencement of the next sub-block of glove drops, there was substantial reversion of the glove toward its original shape as potential energy stored through its deformation was converted back to kinetic energy.

4) The change in the qualities of the glove padding then became the predominant influence on glove performance, reducing the time taken for it to reach a given level of compression, with attendant increase in the rate of change of momentum producing higher peak forces and peak rates of force development.

5) During the 73-minute interval between Blocks 4 and 5 of the drop testing experiment, there was partial recovery of the qualities of the glove padding, but not enough to restore it to the level of performance that it demonstrated prior to Drop 141.

There is some evidence to support the notion of an increased contact surface area for Drops 142 and 143, since the force plate impact profiles provided by the Kistler Bioware software for these drops were "thicker" than those for drops performed beforehand and afterwards. While our direct observations may well be open to other interpretations, it can be stated with certainty that 140 drops of the Std $10 \mathrm{oz}$ glove under the conditions of our experiment produced changes in glove performance that were quite minor compared to those inducible by more traumatic impact.

Our findings have important practical implications. Experimental designs for future research entailing glove comparisons will need to exclude potential order effects created by change in the material properties of any coverings used to protect force-measuring instruments. It now seems that such change can occur even in circumstances where the baseline properties of the covering seem close to ideal, and that in situations where two identically performing gloves are consecutively assessed it may cause the glove tested second to seem inferior. Although this potential order effect appears to be quite small relative to the differences in performance between Std $10 \mathrm{oz}$ and ARLI gloves, it could affect the quantification of those differences, and confound comparison of different prototypes of a specific glove type. Modelling of changes of glove performance with repeated impacts, as accomplished through this study, offers a prospect for mathematical correction of order effects, but we have so far developed models only for two glove types and a single drop height, and have not explored interactions that might arise from variations in experimental protocols. For example, it is possible that testing of an ARLI glove could have relatively little influence on the results of subsequent testing of a Std $10 \mathrm{oz}$ glove, but that the reverse might not be true. Much more extensive and complex modelling would be needed to ensure precision of mathematical corrections.

It may be preferable to either seek a more impact-resistant protective material or to interweave the testing of gloves so that each is subject to only a few impacts 
before being replaced and then reinstated. The latter approach would have the disadvantage of increasing likelihood of error caused by continual "reseating" of gloves on the impacting device, and determination of the extent of this error relative to that produced by an order effect therefore would be necessary.

It is noteworthy that many devices used to measure impact forces produced by boxers have incorporated protective padding [16] [17] [22] [23]. This has been thought essential to safeguard not only the devices but also the hands of the boxers [16]. Our results suggest that whenever padding is included consideration must be given to the possibility that the measurements might be influenced by changes to properties of the padding over the course of a series of impacts. Multiple calibrations of the measurement system throughout each testing session might be needed to ensure the integrity of the data. Additionally, it is entirely possible that padded protective equipment used by boxers (and participants in other combat sports) might become progressively less effective within the confines of a sparring session or a bout, and/or with employment in several contests during a day. The padding in such equipment often includes EVA foam [21].

The most salient outcome of our study, however, is reinforcement of the case for use of pneumatic gloves to enable safer boxing.

We have now demonstrated that in their current iteration these gloves acutely diminish peak impact forces and rates of force development, decrease upward drift in these variables with exposure to numerous high-energy impacts, and have a high level of structural robustness. We recognise that intervals between successive impacts were longer in our experiment than often occurs in the real world, where two or more punches may be delivered within a second. The comparative abilities of conventional and pneumatic gloves to effectively damp all impacts in such a rapid sequence remain to be determined. If it can be proven that pneumatic gloves are not inferior in this regard, there will be a strong rationale for their further development and the conduct of extensive field trials.

We have previously published a review of arguments for and against boxing [24]. There is no doubt that the sport exposes participants to risk of serious injury. Between 1890 and 2007, more than 1200 boxers died either in the ring or within a few days after leaving it, with subdural hematoma being the most common cause [25]. Amateur boxers accounted for almost a quarter of the fatalities. From 1990 to 2008, there was average of almost 2000 presentations per year to United States Emergency Departments for head or neck injuries sustained in boxing [26], raising concerns about possible sequalae, since neurological damage can lead to debilitating functional deficits later in life [27] [28] [29]. Occurrence of rib fractures, pneumothorax, myocardial contusion, spleen rupture and injury to other abdominal organs is also well-documented [30] [31] [32] [33] [34]. In their current form, pneumatic boxing gloves do not reduce peak impact forces or peak rates of force development enough to eliminate the injury risks, but they do have potential to reduce overall injury incidence and severity.

Our primary aim, though, is to support ongoing evolution of modified versions of boxing in which risk of serious injury is minimal and lifelong participa- 
tion is therefore facilitated. Such versions presently exist in a fledgling state [35], with prohibition of impacts to the head and neck among their fundamental characteristics, but their long-term viability will likely require progressive refinement of highly effectual protective equipment, establishment of new rules, customised education programs for coaches and athletes, specialised teaching of skills and perhaps even creation of novel models of competition. Pursuit of this diverse array of tasks constitutes a substantial challenge that will be met only if a sufficiently broad, expert and focused collaborative effort emerges. Even so, the advances being made in the iterative development and evaluation of pneumatic gloves represent a major step toward realising the objective.

\section{Conclusion}

Pneumatic boxing gloves of the type used in our experiment show considerable promise as one means to enable safer boxing. Their effectiveness in damping impacts exceeds that of conventional gloves. They retain structural integrity after a long series of high-energy impacts. Although they do not prevent some upward drift of peak impact forces and peak rates of force development in response to numerous impacts, the drift is less than that seen with conventional gloves. A strong case exists for continuing exploration of the practical utility of pneumatic gloves and their potential influence on rates and types of boxing injury. In particular, the gloves could prove to be a fillip for emergence of modified forms of boxing designed to emphasise safety.

\section{Acknowledgements}

The research reported in this paper was supported by grants from the Australian Olympic Committee (through the international Olympic Solidarity Program) and the Queensland Academy of Sport. Dr Christopher Barnes of the University of Canberra assisted greatly with data collection. Geordie Ferguson of Stellen Studio was responsible for manufacture of the prototype pneumatic glove. Anthony Ashmore of AJA Engineering designed and constructed key elements of our experimental apparatus, as did Katie and Luke Eldridge, both of whom also provided mathematical and engineering advice. Bill Shelley of the University of Canberra and Michael Steinebronn and Jamie Plowman of the Australian Institute of Sport made themselves readily available as technical consultants. Valuable input was provided also by Associate Professor Stephen Trathen of the University of Canberra and Dr Richard Helmer of Superinteractive Pty Ltd. The Canberra Police Community Youth Club played an important role in strongly encouraging the development and testing of pneumatic gloves.

\section{Conflicts of Interest}

The authors declare no conflicts of interest regarding the publication of this paper.

\section{References}

[1] Perkins, P., Jamieson, A., Spratford, W. and Hahn, A. (2018) Evaluation of Ability 
of Two Different Pneumatic Boxing Gloves to Reduce Delivered Impact Forces and Improve Safety. World Journal of Engineering and Technology, 6, 457-491. https://doi.org/10.4236/wjet.2018.62028

[2] Walilko, T.J., Viano, D.C. and Bir, C.A. (2005) Biomechanics of the Head for Olympic Boxer Punches to the Face. British Journal of Sports Medicine, 39, 710-719. https://doi.org/10.1136/bjsm.2004.014126

[3] Perkins, P., Jamieson, A., Spratford, W. and Hahn, A. (2018) Performance of Prototype Pneumatic Boxing Gloves under Two Different Conditions of Target Padding. World Journal of Engineering and Technology, 6 603-624. https://doi.org/10.4236/wjet.2018.63037

[4] (2009) Compubox Review: Worst Title Fight Decisions. https://www.boxingscene.com/compubox-review-worst-title-fight-decisions--24007

[5] Hahn, A., Helmer, R., Kelly, T., Partridge, K., Krajewski, A., Blanchonette, I., et al. (2010) Development of an Automated Scoring System for Amateur Boxing. Procedia Engineering, 2, 3095-3101. https://doi.org/10.1016/j.proeng.2010.04.117

[6] Bruch, H., Hahn, A.G., Helmer, R.J., Mackintosh, C., Blanchonette, I. and McKenna, M.J. (2011) Evaluation of an Automated Scoring System in a Modified Form of Competitive Boxing. Procedia Engineering, 13, 445-450. https://doi.org/10.1016/j.proeng.2011.05.112

[7] Furkan (2017) How Long Do Boxing Gloves Last? The Complete Guide. https://findbestboxinggloves.com/how-long-do-boxing-gloves-last-the-complete-gu ide/

[8] (2018) How Long Do Boxing Gloves Last? https://tenreviwed.com/how-long-do-boxing-gloves-last/

[9] Foam Specifications Explained. http://www.prfloors.com/PDF/Ultralon\%20spec\%20explained.pdf

[10] Smith, P.K. and Hamill, J. (1985) Karate and Boxing Glove Impact Characteristics as Functions of Velocity and Repeated Impact. In: Terauds, J. and Barham, J.N., Eds., Biomechanics in Sports II, Academic Publishers, Del Mar, CA, 123-133.

[11] Lee, B. and McGill, S. (2014) Striking Dynamics and Kinetic Properties of Boxing and MMA Gloves. Revista de Artes Marciales Asiáticas, 9, 106-115. https://doi.org/10.18002/rama.v9i2.1175

[12] Chadli, S., Ababou, N., Ababou, A. and Ouadahi, N. (2018) Quantification of Boxing Gloves Damping: Method and Apparatus. Measurement, 129, 504-517. https://doi.org/10.1016/j.measurement.2018.07.036

[13] (2018) Sparring Gloves: What to Know and Why? https://www.stingsports.com.au/blogs/news/sparring-gloves-what-to-know-and-why

[14] Mack, J., Stojsih, S., Sherman, D., Dau, N. and Bir, C. (2010) Amateur Boxing Biomechanics and Punch Force. Proceedings of 28 th Conference of International Society of Biomechanics in Sports, Marquette, MI, 19-23.

[15] Pierce, J.D., Reinbold, K.A., Lyngard, B.C., Goldman, R.J. and Pastore, C.M. (2006) Direct Measurement of Punch Force during Six Professional Boxing Matches. Journal of Quantitative Analysis in Sports, 2, 1-17. https://doi.org/10.2202/1559-0410.1004

[16] Atha, J., Yeadon, M.R., Sandover, J. and Parsons, K.C. (1985) The Damaging Punch. British Medical Journal, 291, 1756-1757.

[17] Smith, M.S., Dyson, R.J., Hale, T. and Janaway, L. (2000) Development of a Boxing Dynamometer and Its Punch Force Discrimination Efficacy. Journal of Sports 
Sciences, 18, 445-450. https://doi.org/10.1080/02640410050074377

[18] Dyson, R., Smith, M., Fenn, L. and Martin, C. (2005) Differences in Lead and Rear Hand Punching Forces, Delivered at Maximal Speed Relative to Maximal Force, by Amateur Boxers. Proceedings of 23rd Conference of International Society of Biomechanics in Sports, Beijing, 869-872.

[19] Viano, D.C., Casson, I.R., Pellman, E.J., Bir, C.A., Zhang, L., Sherman, D.C., et al. (2005) Concussion in Professional Football: Comparison with Boxing Head Impacts Part 10. Neurosurgery, 57, 1154-1172. https://doi.org/10.1227/01.NEU.0000187541.87937.D9

[20] Piorkowski, B.A., Lees, A. and Barton, G.B. (2011) Single Maximal versus Combination Punch Kinetics. Sports Biomechanics, 10, 1-11. https://doi.org/10.1080/14763141.2010.547590

[21] What Is an EVA Foam and Its Common Uses? Foam Sealant Pty Ltd. https://foamsealant.com.au/what-is-an-eva-foam-and-its-common-uses/

[22] Halperin, I., Chapman, D.W., Martin, D.T. and Abbiss, C. (2017) The Effects of Attentional Focus Instructions on Punching Velocity and Impact Forces among Trained Combat Athletes. Journal of Sports Sciences, 35, 500-507. https://doi.org/10.1080/02640414.2016.1175651

[23] Perkins, P., Jamieson, A., Ferguson, G., Spratford, W. and Hahn, A. (2018) Iterative Design of Impact-Damping Gloves for Safer Boxing. Open Journal of Safety Science and Technology, 8, 49-97. https://doi.org/10.4236/ojsst.2018.83005

[24] Perkins, P., Hahn, A., Lucas, R. and Keegan, R. (2014) The Boxing Conundrum: Is There a Place for a New Variant of the Sport? Journal of Research in Humanities and Social Science, 2, 9-25.

[25] Svinth, J. (2007) Death under the Spotlight: Analysing the Data. Journal of Combative Sport, 1-19.

[26] Potter, M.R., Snyder, A.J. and Smith, G.A. (2011) Boxing Injuries Presenting to U.S. Emergency Departments, 1990-2008. American Journal of Preventive Medicine, 40, 462-467. https://doi.org/10.1016/j.amepre.2010.12.018

[27] Lundberg, G. (1993) Medical Arguments for Nonparticipation in Boxing. In: Medical Aspects of Boxing, CRC Press, Boca Raton, 11-15.

[28] McCrory, P., Zazryn, T. and Cameron, P. (2007) The Evidence For Chronic Traumatic Encephalopathy in Boxing. Sports Medicine, 37, 467-476. https://doi.org/10.2165/00007256-200737060-00001

[29] Pineda, P. and Gould, D. (2010) The Neuroanatomical Relationship of Dementia Pugilistica and Alzheimer's Disease. Neuroanatomy, 9, 5-7.

[30] Oelman, B.J., Rose, C.M.E. and Arlow, K.J. (1983) Boxing Injuries in the Army. Journal of the Royal Army Medical Corps, 129, 32-37. https://doi.org/10.1136/jramc-129-01-10

[31] Belham, G.J. and Adler, M. (1985) Case Report: Pneumothorax in a Boxer. British Journal of Sports Medicine, 19, 45. https://doi.org/10.1136/bjsm.19.1.45

[32] Bellotti, P., Chiarella, F., Domenicucci, S., Lupi, G. and Vecchio, C. (1992) Myocardial Contusion after a Professional Boxing Match. American Journal of Cardiology, 69, 709-710. https://doi.org/10.1016/0002-9149(92)90175-X

[33] Timm, K.E., Wallach, J.M., Stone, J.A. and Ryan, E.J. (1993) Fifteen Years of Amateur Boxing Injuries/Illnesses at the United States Olympic Training Center. Journal of Athletic Training, 28, 330-334.

[34] Associated Press (2012) Teen Boxer Died of Ruptured Spleen. San Diego Un- 
ion-Tribune.

http://www.sandiegouniontribune.com/sdut-teen-boxer-died-of-ruptured-spleen-2 012sep26-story.html

[35] Hahn, A.G., Helmer, R.J., Mackintosh, C., Staynes, L.M. and Blanchonette, I. (2011) Technological Foundations and Current Status of a Modified, Low-Risk Form of Competitive Boxing (Box’ Tag ${ }^{\oplus}$ ). Sports Technology, 4, 178-184.

https://doi.org/10.1080/19346182.2012.725413 